\title{
Automated volcanic eruption detection using MODIS
}

\author{
Robert Wright*, Luke Flynn, Harold Garbeil, Andrew Harris, Eric Pilger \\ Hawaii Institute of Geophysics and Planetology, University of Hawaii, Honolulu, HI, USA
}

Received 12 October 2001; received in revised form 22 February 2002; accepted 4 March 2002

\begin{abstract}
The moderate resolution imaging spectroradiometer (MODIS) flown on-board NASA's first earth observing system (EOS) platform, Terra, offers complete global data coverage every 1-2 days at spatial resolutions of 250,500 , and $1000 \mathrm{~m}$. Its ability to detect emitted radiation in the short $(4 \mu \mathrm{m})$ - and long $(12 \mu \mathrm{m})$-wave infrared regions of the electromagnetic spectrum, combined with the excellent geolocation of the image pixels $(\sim 200 \mathrm{~m})$, makes it an ideal source of data for automatically detecting and monitoring high-temperature volcanic thermal anomalies. This paper describes the underlying principles of, and results obtained from, just such a system. Our algorithm interrogates the MODIS Level 1B data stream for evidence of high-temperature volcanic features. Once a hotspot has been identified, its details (location, emitted spectral radiance, satellite observational parameters) are written to an ASCII text file and transferred via file transfer protocol (FTP) to the Hawaii Institute of Geophysics and Planetology (HIGP), where the results are posted on the Internet (http:// modis.higp.hawaii.edu). The global distribution of volcanic hotspots can be examined visually at a variety of scales using this website, which also allows easy access to the quantitative data contained in the ASCII files themselves. We outline how the algorithm has proven robust as a hotspot detection tool for a wide range of eruptive styles at both permanently and sporadically active volcanoes including Soufriere Hills (Montserrat), Popocatépetl (Mexico), Bezymianny (Russia), and Merapi (Java), amongst others. We also present case studies of how the system has allowed the onset, development, and cessation of discrete eruptive events to be monitored at Nyamuragira (Congo), Piton de la Fournaise (Réunion Island), and Shiveluch (Russia). C 2002 Published by Elsevier Science Inc.
\end{abstract}

\section{Introduction}

Volcanism is synonymous with heat, and over the last two decades, much research has been dedicated to studying how thermal infrared satellite data can be used to monitor the eruptive state of active volcanoes. This research can be conveniently divided into two groups (Flynn, Harris, \& Wright, 2001). Initial research was concerned with the use of high-spatial-, low-temporal-resolution data from the Landsat thematic mapper (TM), with Francis and McAllister (1986) the first to use TM data to detect short-wave infrared (SWIR) radiance emitted from a growing lava dome at the summit of Lascar Volcano in northern Chile. Subsequently, several authors have used TM and its successor, the Landsat 7 enhanced thematic mapper plus $(\mathrm{ETM}+)$, to analyse the detailed thermal properties of active lava flows (e.g. Flynn

\footnotetext{
* Corresponding author. Present address: Department of Geography and Earth Sciences, Brunel University, Uxbridge UB8 3PH, UK. Fax: +441895-203217.

E-mail address: robert.wright@brunel.ac.uk (R. Wright).
}

Mouginis-Mark, \& Horton, 1994; Wright, Flynn, \& Harris, 2001), lava domes (e.g. Oppenheimer, Francis, Rothery, Carlton, \& Glaze, 1993; Wooster, Kaneko, Nakada, \& Shimizu, 2000), lava lakes (e.g. Harris, Flynn, Rothery, Oppenheimer, \& Sherman, 1999), and fumarole fields (e.g. Harris \& Stevenson, 1997).

Although the high-spatial-resolution $(30-120 \mathrm{~m}$ per pixel) data provided by TM, ETM+, and the recently launched advanced spaceborne thermal emission and reflection radiometer (ASTER) are useful for spatially detailed thermal analysis, their relatively poor temporal resolution (16-day revisit period) means that they do not lend themselves to routine thermal monitoring. For example, although the 1991-1993 eruption of Mount Etna lasted for 473 days, only five cloud-free TM acquisitions were possible (Wright, Rothery, Blake, \& Pieri, 2000). As a result, volcanologists have looked to low-spatial- but high-temporal-resolution data from sensors such as the advanced very high resolution radiometer (AVHRR), geostationary operational environmental satellite series (GOES), and the along-track scanning radiometer (ATSR) to satisfy the need for an operational volcano monitoring capability. 
AVHRR, GOES, and ATSR have proven to be effective eruption monitoring tools, in spite of the fact that the volcanic features of interest are often much smaller than the pixel size of the instruments (AVHRR $\sim 1 \mathrm{~km}$; ATSR $\sim 1 \mathrm{~km}$; GOES $\sim 4 \mathrm{~km}$ ). This success stems from their relatively high sampling frequency and their ability to measure emitted radiance in the SWIR region of the electromagnetic spectrum, a region in which volcanic hotspots emit prodigious amounts of energy. By utilising nighttime and daytime passes, AVHRR data can be acquired four times per day for any given ground target, although this frequency increases if more than one NOAA satellite is orbiting at any one time and at high latitudes where adjacent swaths overlap significantly. ATSR data are acquired twice in every 24-h period, while GOES provides a fan image of the Earth, on average, every $15 \mathrm{~min}$. This high sampling frequency reduces the chance that a ground target will be obscured by clouds and is ideal for monitoring dynamic volcanic phenomena. AVHRR has been used to provide detailed chronologies of effusive eruptions at Mount Etna, Sicily (Harris, Blake, Rothery, \& Stevens, 1997; Harris \& Neri, in press), and is used by the Alaskan Volcano Observatory (AVO) to routinely monitor the many active volcanoes that exist in the North Pacific region (Dehn, Dean, \& Engle, 2000; Schneider, Dean, Dehn, Miller, \& Kirianov, 2000).

Since 1998, GOES data have been used as the basis for an automated volcano monitoring system based at the HIGP (Harris, Flynn, et al., 2000; Harris et al., 2001). Using direct-broadcast GOES data provided by the Naval Research Laboratory (Monterrey, CA), the system searches for volcanic hotspots within several $500 \times 500$ pixel image "tiles" covering areas including the Lesser Antilles, Hawaii, South and Central America, New Zealand, and the continental USA. The results are posted on the Internet (http://goes.higp.hawaii.edu) usually within 15 min of initial image acquisition. The GOES-based system has provided valuable insights into the development of lava flow-fields and eruption timings at Kilauea Volcano in Hawaii (Harris, Keszthelyi, et al., 1997; Harris \& Thornber, 1999) and Fernandina Volcano in the Galapagos Islands (Mouginis-Mark, Snell, \& Ellisor, 2000). It has also been used to elucidate processes governing the behaviour of potentially explosive silicic lava domes at Popocatépetl, Mexico (Wright, de la Cruz-Reyna, Flynn, Harris, \& Gomez-Palacios, in press) and Lascar (Harris, Pilger, \& Flynn, 2002).

Although not used in an operational mode at this time, several studies have illustrated the value of ATSR for monitoring volcanic activity at Lascar, Chile (Wooster, 2001), Unzen, Japan (Wooster \& Kaneko, 1998), and Mount Etna (Rothery, Coltelli, Pirie, Wooster, \& Wright, 2001). ATSR acquires data in four infrared wavebands at a spatial resolution of $\sim 1 \mathrm{~km}$ at nadir. One nighttime and one daytime image are acquired for each point on the Earth's surface, on average, once every 3 days.

Although AVHRR and GOES are commonly used to monitor active volcanoes, neither has been integrated into a fully global system. AVHRR is only used routinely in the North Pacific, while the use of GOES is limited to the Americas and the Pacific. As a result, volcanically active areas of the globe such as Iceland, the Mediterranean, and the African Rift remain unmonitored by existing systems. The moderate resolution imaging spectroradiometer (MODIS), launched on-board NASA's first earth observing system (EOS) platform "Terra" in December 1999, is the latest space-based sensor to provide the kind of low-spatial-, high-temporal-resolution data previously described. The purpose of this paper is to show how MODIS has been used as the basis for a global volcanic eruption detection system.

\section{Principles of low-spatial-resolution volcano monitoring}

Before describing the MODIS detection algorithm in detail, we will first review the physical principles upon which low spatial thermal monitoring of hotspots is based. AVHRR and GOES form the basis of two existing volcano monitoring systems (e.g. Dehn et al., 2000; Harris, Flynn, et al., 2000) primarily because they detect radiance in spectral wavebands centered at 4 and $11-12 \mu \mathrm{m}$. These wavebands coincide with the wavelengths of peak emission for high-temperature volcanic heat sources and ambient Earth surface temperatures, respectively. Research into hotspot detection using low-spatial-resolution satellite data has exploited the fact that the presence of a high-temperature, subpixel-sized hotspot, within an otherwise thermally homogenous pixel radiating at ambient temperature, causes the amount of radiance emitted in the SWIR to increase dramatically when compared to that in the long-wave infrared (Dozier, 1981). For example, a thermally homogenous $1-\mathrm{km}$ pixel containing ground at 300 $\mathrm{K}$ will emit 0.4 and $9.5 \mathrm{~W} \mathrm{~m}^{-2} \mathrm{sr}^{-1} \mu \mathrm{m}^{-1}$ at 4 and $11 \mu \mathrm{m}$, respectively. However, if an active lava body radiating at 850 $\mathrm{K}$ occupies $0.05 \%$ of this pixel $\left(500 \mathrm{~m}^{2}\right)$ the integrated radiance (i.e. from the lava feature and the adjacent background) emitted at 4 and $11 \mu \mathrm{m}$ increases to 1.3 and $9.6 \mathrm{~W}$ $\mathrm{m}^{-2} \mathrm{sr}^{-1} \mu \mathrm{m}^{-1}$, respectively. Thus, although the presence of a subpixel-sized hotspot causes emission at $11 \mu \mathrm{m}$ to increase by only $1 \%$, the presence of the same feature causes emission at $4 \mu \mathrm{m}$ to increase by more than $200 \%$.

Remotely sensed infrared radiance data therefore provide a tool that is well suited to identifying volcanic hotspots at the pixel or subpixel scale. Section 3 reviews the properties of MODIS that make it suitable for hotspot monitoring and, in certain aspects, preferential to GOES and AVHRR for this purpose.

\section{The Moderate Resolution Imaging Spectroradiometer (MODIS)}

MODIS was launched into a sun-synchronous polar orbit on-board NASA's first EOS platform, Terra, in December 
1999. Terra (previously called EOS AM-1) has a 10:30 a.m. descending-node equatorial crossing time, providing one daytime and one nighttime image in a $24-\mathrm{h}$ period. Although adjacent imaging swaths overlap significantly at high latitudes, gaps between adjacent swaths occur close to the equator, and, as a result, complete global coverage is achieved every 2 days. A second MODIS sensor is due to be launched in April 2002 on the next EOS platform "Aqua" (previously called EOS PM-1). As its former name suggests, Aqua will have an afternoon (2:30 p.m.) descending-node equatorial crossing time.

In terms of hotspot detection, several features are of particular relevance. MODIS acquires data in the important 4- and $11-\mu \mathrm{m}$ regions of the electromagnetic spectrum. However, whereas AVHRR and GOES provide only three suitable spectral channels, MODIS provides up to 10 . Of these, three are used by the MODVOLC algorithm that we describe in this paper; Bands 21, 22, and 32. Bands 21 and 22 both detect radiance in the same spectral interval (3.929$3.989 \mu \mathrm{m}$ ), with a radiometric accuracy (expressed as noise equivalent temperature variation; $\mathrm{NE} \Delta \mathrm{T}$ ) of 2.0 and $0.07 \mathrm{~K}$, respectively. Significantly, although Band 22 has a saturation temperature of $\sim 330 \mathrm{~K}$, Band 21, also known as the "fire channel," was designed to have a saturation temperature of $\sim 500 \mathrm{~K}$ (Barnes, Pagano, \& Salomonson, 1998). Unfortunately, Band 21 was only calibrated to a temperature of $\sim 340 \mathrm{~K}(3.5 \%$ of its full dynamic range) prior to launch, and, as a result, Band 21 data acquired during the first 9 months of MODIS operation are useless for precise quantitative purposes. However, thanks to a vicarious lunar calibration performed in November 2000, Band 21 is now calibrated to a temperature of $\sim 400 \mathrm{~K}$ (the brightness temperature equivalent to Lunar reflectance at $4 \mu \mathrm{m}$ ). Despite these initial problems, Band 21 is a welcome addition to the MODIS sensor, given the ease with which the AVHRR and GOES 4- $\mu$ m channels saturate over hightemperature sources. Band 32 (which images between 11.770 and $12.270 \mu \mathrm{m} ; \mathrm{NE} \Delta \mathrm{T}=0.05 \mathrm{~K}$ ) also has a higher saturation brightness temperature $(420 \mathrm{~K})$ than its longwave infrared counterparts on AVHRR and GOES. Although the specified geometric accuracy of the MODIS pixels was $300 \mathrm{~m}$, postlaunch corrections for bias in the roll, pitch, and yaw of the Terra platform mean that an accuracy of $200 \mathrm{~m}$ can be expected. The geolocation of MODIS pixels (which is $1 \mathrm{~km}$ for Bands 21, 22, and 32) is therefore well suited to the task of mapping the spatial distribution of volcanic hotspots.

Each MODIS image covers an area of approximately $1354 \times 2030 \mathrm{~km}$. Scanning is achieved by 10 simultaneous $1-\mathrm{km}$ strips (i.e. one strip per detector giving a $10-\mathrm{km}$ footprint) or 20 and 40 strips for the $500-$ and $250-\mathrm{m}$ resolution channels, respectively (Kaufman et al., 1998). Although the nominal MODIS pixel size at 4 and $11-12 \mu \mathrm{m}$ is $1 \mathrm{~km}$, a point heat source is likely to be represented by one or two across-track pixels. This is because the response function of MODIS is triangular in the across-track direction

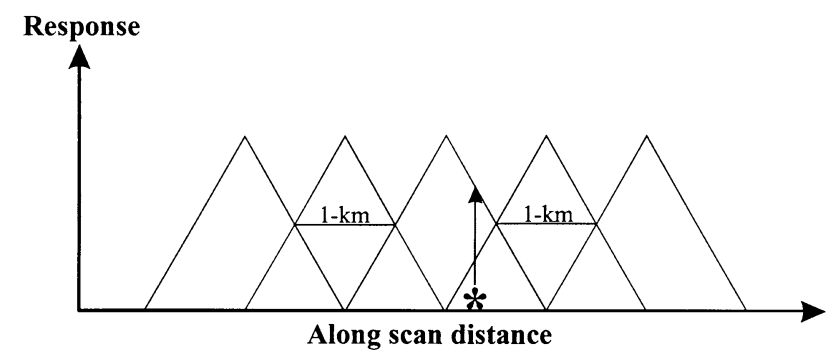

Fig. 1. MODIS across-track response and the definition of the MODIS pixel. A hotspot at a given ground location (asterisk) can be observed by two adjacent pixels (arrow). Adapted from Fig. 4 in Kaufman et al. (1998).

(Fig. 1). This does not, however, lead to "double counting" of radiance, as although the radiance from a hotspot may be shared between two pixels, the sampling period (dwell time) is always the same $(\sim 333 \mu \mathrm{s})$.

\section{The MODIS volcano detection algorithm: MODVOLC}

The algorithm currently uses nighttime MODIS data only, and it is the development of the nighttime MODVOLC algorithm that we describe here. However, in order to fully understand the rationale upon which the algorithm was designed, it is first necessary to outline the operational constraints that guided its development. MODVOLC had to be designed to run at an early stage in the MODIS data chain with no other data dependencies (Kaufman et al., 1998) and had to be simple enough so as not to impose a drain on the Goddard Space Flight Center (GSFC) Distributed Active Archive Center's (DAAC) computer resources. The MODVOLC algorithm had to be a point operation (i.e. pixel by pixel), using no more than eight mathematical operations and five bands of MODIS data. The resultant data files had to small enough to not take up significant amounts of space at the DAAC and could not be archived on site (Flynn, Wright, Garbeil, Harris, \& Pilger, 2002).

\subsection{A review of previous automatic hotspot detection methods}

Although manual identification of hotspots is relatively simple using $4-\mu \mathrm{m}$ data, automatic (i.e. noninteractive) detection is more complex because an appropriate threshold radiance value must be chosen to distinguish those pixels that contain hotspots from those that do not. This difficulty stems from the complex nature of the 4- $\mu \mathrm{m}$ radiance signal, because although 4- $\mu \mathrm{m}$ data are effective in highlighting the hotspots, they also record variations in the background temperature of the surfaces surrounding the hotspot. This makes it difficult to identify automatically hotspots at the global scale using a single $4-\mu \mathrm{m}$ radiance threshold, as any such value will fail to account for seasonal and geographical variations in the ambient background temperature. The 
situation is complicated further when using daytime data due to the contribution that reflected sunlight makes to the 4- $\mu \mathrm{m}$ signal, which can result in anomalously reflective surfaces appearing "hot" in daytime 4- $\mu \mathrm{m}$ imagery.

These problems provided the impetus for more robust techniques for automatically detecting hotspots in satellite data to be developed. Such algorithms generally combine two distinct approaches: the spectral comparison method and the spatial comparison method. The spectral comparison method is based on the fact that 4- and 11-12- $\mu \mathrm{m}$ brightness temperatures should be very similar for surfaces at ambient temperature, varying by only a few degrees due to differences in atmospheric transmissivity and target emissivity (although wide departures can occur over clouds). As such, it requires that the satellite radiance data are converted to brightness temperatures, as measured radiance at 4 and $11-12 \mu \mathrm{m}$ is markedly different, even for thermally homogenous surfaces. The presence of a high-temperature radiator causes the $4-\mu \mathrm{m}$ brightness temperature to increase dramatically when compared to the $11-\mu \mathrm{m}$ brightness temperature recorded for the same pixel. The magnitude of this temperature difference largely depends on the hotspot size and its temperature. The spectral comparison method is a much more robust way to detect hotspots than simply thresholding raw $4-\mu \mathrm{m}$ radiance data, because it automatically accommodates changes in the ambient background temperature and solar heating effects. The method has been used successfully as a basis for discriminating wildfires (Prins \& Menzel, 1992) and active lava flows (Harris, Swabey, \& Higgins, 1995).

The spatial comparison method assumes that the 4- $\mu \mathrm{m}$ brightness temperature of a hotspot pixel will be significantly different to that of neighbouring background pixels (Flasse \& Ceccato, 1996). By assuming that each pixel in an image is a "potential" hotspot and statistically comparing its $4-\mu \mathrm{m}$ brightness temperature to that of its neighbours, positive discrimination of hotspots can be achieved when the temperature difference exceeds a certain threshold. Sometimes called the "contextual approach," it accommodates the influence of seasonal and geographical effects on the $4-\mu \mathrm{m}$ signal by tailoring the threshold for positive detection to the prevailing local background.

Hybrids of the spectral and contextual approaches form the basis of several existing hotspot detection algorithms, such as the GOES automated biomass burning algorithm (ABBA; Prins \& Menzel, 1994), the MODIS fire algorithm (Kaufman et al., 1998), and the HIGP GOES hotspot algorithm (Harris et al., 2001). However, the constraints placed on the development of MODVOLC meant that we could not utilise either approach. Restrictions on the number of mathematical operations available prevented conversion of the MODIS Level 1B radiance products to brightness temperatures (thus excluding the spectral discrimination method), while the necessity for the algorithm to run as a point operation meant that contextual analysis could not be performed. As a result, we have developed an adapted algorithm to threshold automatically volcanic hotspots in MODIS data within the imposed operational constraints.

\subsection{MODVOLC: theoretical background and algorithm development}

The nature of the relationship between temperature and radiance at $3.959 \mu \mathrm{m}$ (MODIS Band 21/22) and $12.02 \mu \mathrm{m}$ (Band 32) offers the possibility for distinguishing thermally homogenous surfaces of differing temperature based on differences in the slope of the Planck curve between these points (Fig. 2). Over the range -80 to $+100{ }^{\circ} \mathrm{C}$ (sufficient to cover the full range of ambient Earth surface temperatures), the difference between the radiance detected at 3.959 and $12.02 \mu \mathrm{m}$ increases as the temperature of the surface increases.

Fig. 3 shows contrast-enhanced Band 22 data from a MODIS Level 1B nighttime image of the Big Island of Hawaii, acquired on 2 February 2001 (MODIS granule ID: MOD021KM.A2001033.0845.002.2001037054959.hdf). For several cover types identified in the image, a sample of 30 pixels was chosen at random for each group, and the difference between the radiance measured in Bands 22 and 32 (i.e. $22-32$ ) was recorded. An active lava flow at Kilauea Volcano was also present on this date (Fig. 3, inset), and Band $22-32$ values were calculated for pixels that appeared thermally anomalous. We use Band 22 data because of its higher radiometric resolution when compared to Band 21, which improves its ability to discriminate between surfaces emitting very similar radiances. However, when Band 22 was saturated, as it was for several lava flow pixels in this image, we used the unsaturated Band 21 values (i.e. $21-32$ ). Fig. 4 shows the results. Clearly, simple subtraction of the radiance measured in Band 32 radiance from that measured in Band 22 or 21 does not distinguish the hot lava flows from the other cover types, with the lava pixels being particularly confused with the "cold" cloud pixel group. This is because although thermally homogenous blackbody surfaces can be discriminated using a simple band subtraction operation (Fig. 2), the presence of subpixel-sized hotspots within the lava pixels causes this simple relationship to break down.

Fig. 5 shows a series of Planck curves for blackbodies radiating at a range of temperatures from -50 to $+13{ }^{\circ} \mathrm{C}$, encompassing the range of nonvolcanic temperatures found in the nighttime Big Island MODIS data set. Low-temperature surfaces (such as clouds and mountain tops) exhibit relatively small 22[21] - 32 values (i.e. a shallow sloping Planck curve between 3.959 and $12.02 \mu \mathrm{m}$ ), while warmer surfaces (such as land at sea level) exhibit relatively larger 22[21] - 32 values (a steeper sloping curve). Land at a homogenous temperature of $13{ }^{\circ} \mathrm{C}$ (such as that immediately adjacent to the active lava flow in this data set) therefore exhibits a greater MODIS Band 22[21]-32 radiance value than do cold clouds. However, the introduction of a subpixel-sized, high-temperature lava flow to such 


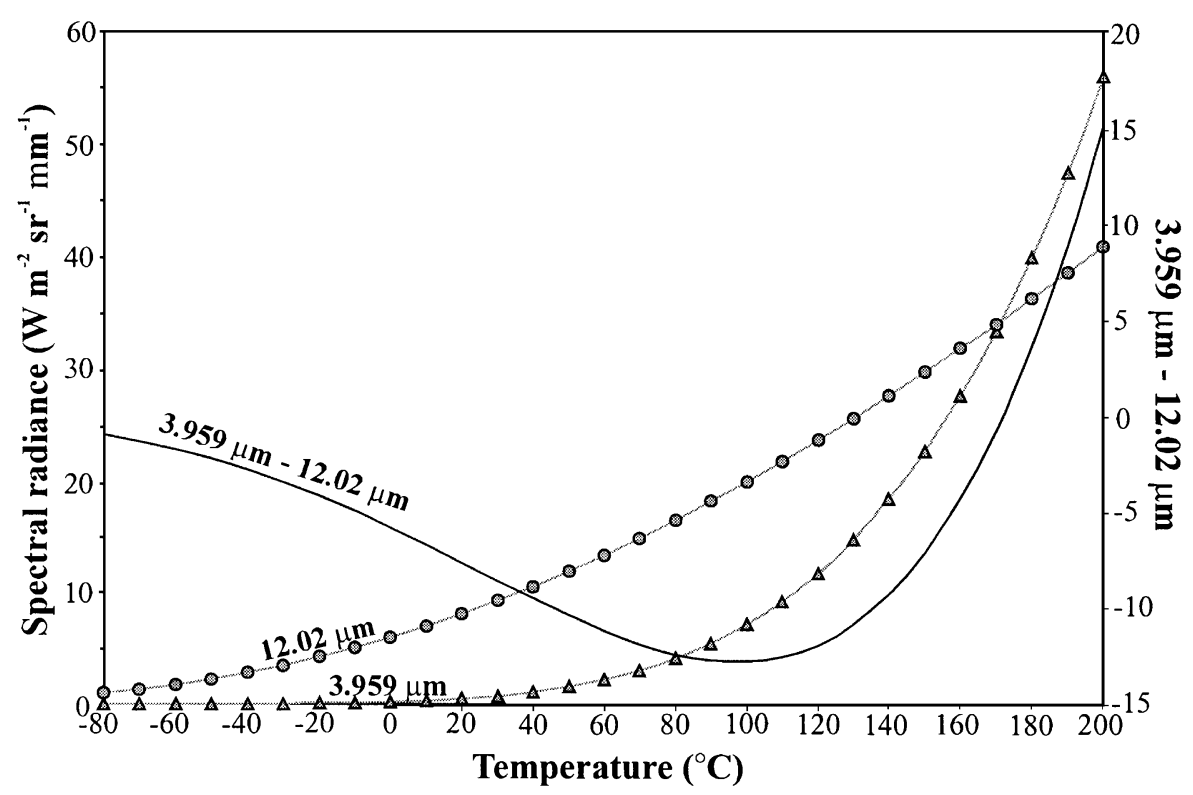

Fig. 2. Planck curves calculated for thermally homogenous surfaces at 3.959 and $12.02 \mu \mathrm{m}$. The $3.959-12.02 \mu \mathrm{m}$ difference is plotted on the right-hand ordinate.

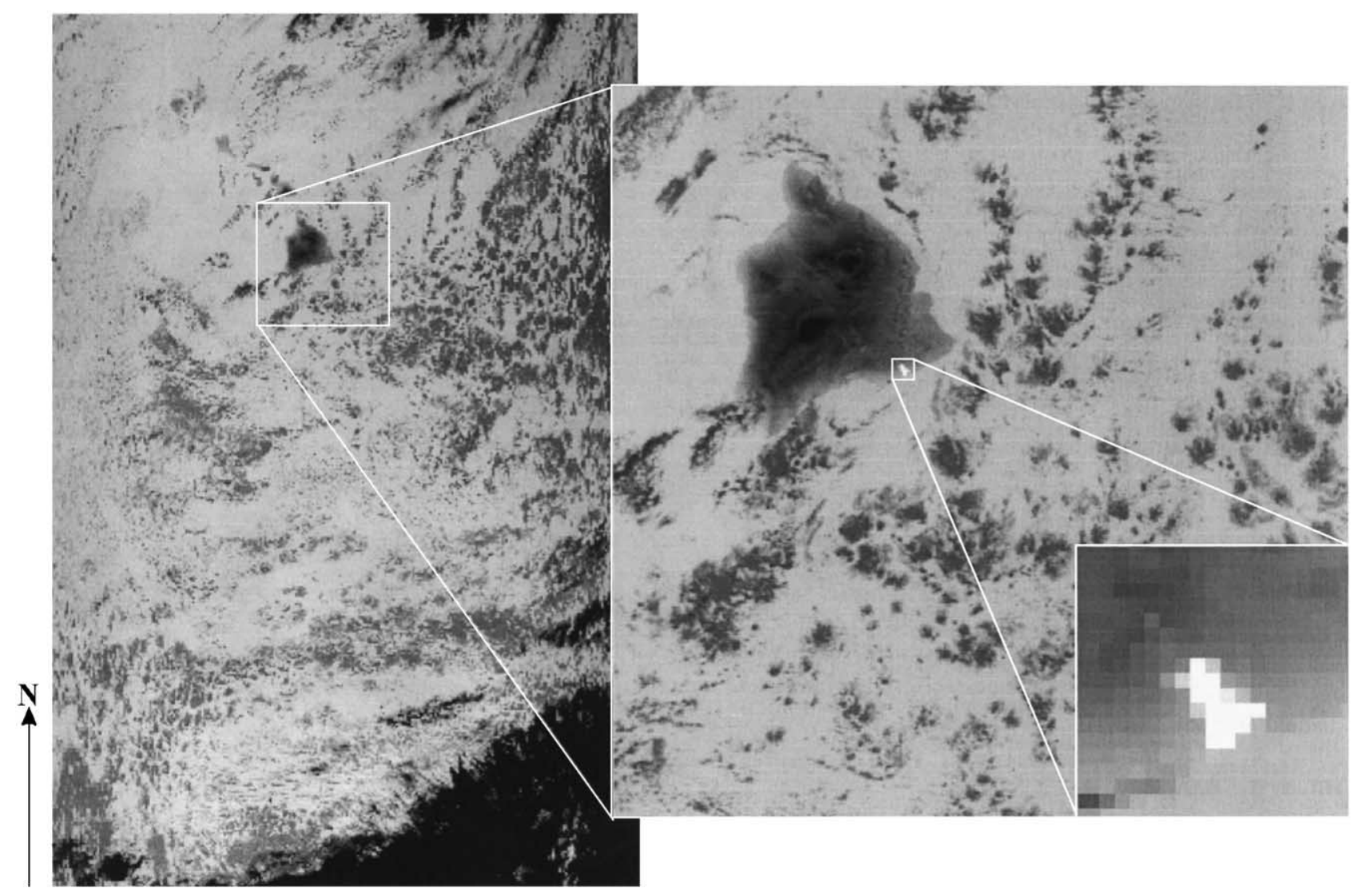

Fig. 3. Contrast-enhanced MODIS Band 22 image of the Big Island of Hawaii, acquired at night on 2 February 2001. The image has been rotated $180^{\circ}$. Main image measures $\sim 2354 \times 1354 \mathrm{~km}$. Active lava flows associated with the ongoing eruption at Kilauea Volcano are obvious as a group of bright pixels in the second inset image. 


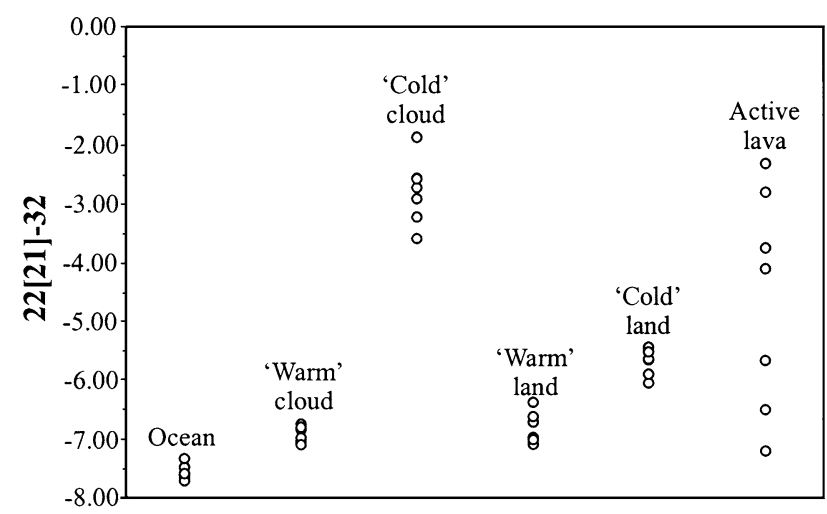

Fig. 4. MODIS band 22[21] - 32 values calculated for several different pixel cover types within the 2 February 2001 Big Island data set.

a pixel causes the amount of radiance emitted at $3.959 \mu \mathrm{m}$ to increase at a much greater rate than at $12.02 \mu \mathrm{m}$, as discussed in Section 2. This has the effect of reducing the slope of the Planck curve between 3.959 and $12.02 \mu \mathrm{m}$ as the size of the hotspot increases. As a result, very cold surfaces and pixels containing subpixel-sized lava flows cannot be discriminated on the basis of the MODIS Band 22[21] - 32 radiance subtraction.

By normalising by the sum of the radiances, however, an index value can be obtained that is weighted to those surfaces that emit substantial amounts of radiance at 3.959 $\mu \mathrm{m}$ (i.e. the lava flows) rather than those that emit lower amounts of radiance at this wavelength. Fig. 6 shows the
Band 22[21] - 32 values for same pixels portrayed in Fig. 4, normalised by the sum of the radiance's (i.e. MODIS band [22-32/22+32], or [21-32/21+32], where the Band 22 detectors were saturated). This approach, which, for convenience, we term a normalised thermal index (NTI), allows much better discrimination between the lava flows and the other cover types within the image, offering the possibility that active hotspot pixels can be automatically discriminated on the basis of an NTI threshold.

Fig. 7 shows the histogram of NTI values calculated for all 2748620 pixels in the 2 February 2001 Big Island data set. The distribution is slightly bimodal with lower values corresponding to relatively cold clouds and the bulk of the higher NTI values corresponding to the ocean pixels that dominate the scene. The inset shows the extreme right-hand tail of the distribution. Manual inspection of the data revealed that each of the 13 pixels with an NTI value of $>-0.80$ contained active lava associated with the ongoing eruption at Kilauea Volcano. In this example, hotspot pixels emitting more radiance at $3.959 \mu \mathrm{m}$ are characterised by higher NTI values. This makes them easier to distinguish than the less intense lava pixels. These pixels, which occupy positions close to the edge of the flow-field and almost certainly contain larger proportions of ground at ambient temperatures, have NTI values closer to those that characterise the ocean, land, and cloud pixels that comprise the bulk of the histogram.

This initial analysis indicated that the NTI, which satisfied the imposed operational constraints, could be an

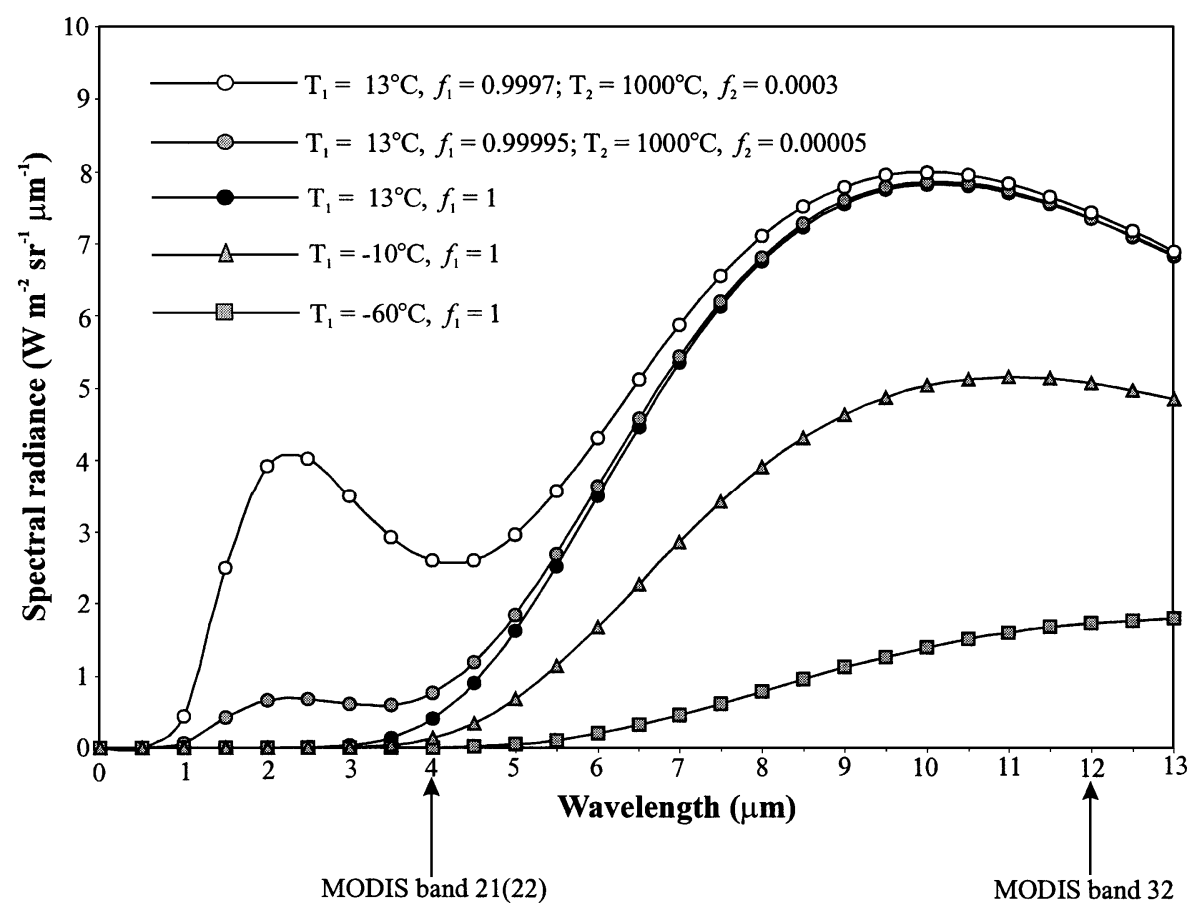

Fig. 5. Planck curves for a range of blackbody surfaces. Planck curves for thermally homogenous surfaces exhibit an increasing slope between 4 and $12 \mu \mathrm{m}$ over the range of temperatures presented. However, this relationship breaks down for pixels containing subpixel-sized radiators, as the amount of radiance emitted at $4 \mu \mathrm{m}$ increases dramatically when compared to the amount emitted at $12 \mu \mathrm{m}$. As a result, hotspot pixels can exhibit similar slopes to cold, thermally homogenous pixels. 


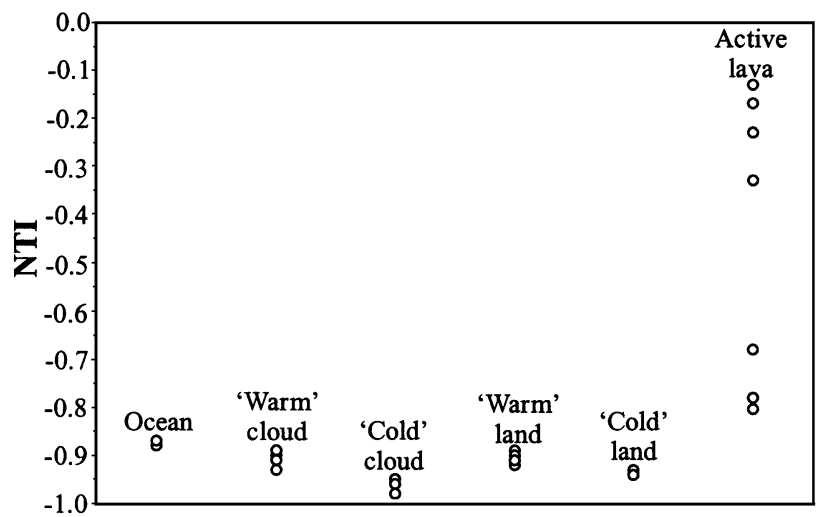

Fig. 6. NTI values calculated for the same pixels as depicted in Fig. 4. The NTI allows active lava pixels to be distinguished from nonvolcanic pixels much more easily than a simple MODIS Band 22[21] - 32 difference.

appropriate means for detecting hotspots with MODIS. As the NTI is based on absolute radiance values, variations in geography and season will influence its value, as MODIS Bands 21, 22, and 32 are all sensitive to variations in the ambient background temperature. However, operational constraints dictated that we establish a single threshold value appropriate for the entire globe. For this reason, we analysed MODIS nighttime images for a range of active volcanoes around the world to empirically establish a single
NTI threshold that would be suitable for detecting volcanic hotspots at the global scale.

Some of the results are shown in Fig. 8. Targets were chosen to exhibit as much variation in background temperatures as possible, with Mount Erebus (Antarctica) and Erta Ale volcano (Ethiopia) end-member examples. In each instance, the extreme right-hand tail of the NTI distribution was composed solely of hotspot pixels (Fig. 8, insets). This confirmed that the NTI approach could be used to automatically identify volcanic hotspots and allowed us to empirically establish a threshold that would identify as many volcanic hotspots as possible without resulting in false alerts.

At Mount Erebus (Fig. 8a), two thermally anomalous pixels associated with the active summit lava lake were apparent through visual inspection of the Band 22 data. A normalised index threshold of -0.80 was sufficient to flag one of these. In order to identify both, a lower threshold of -0.84 would need to be implemented. However, such a value would be unstable as a means for detecting hotspots at the global scale. The fact that land and ocean temperatures in Ethiopia are much higher than those in Antarctica causes the histogram of NTI values for Erta Ale to shift to more positive values when compared to that of Erebus. This positive shift in the NTI histogram means that a threshold of -0.84 , although appropriate for Erebus (and by extension the many active volcanoes that reside in Kamchatka

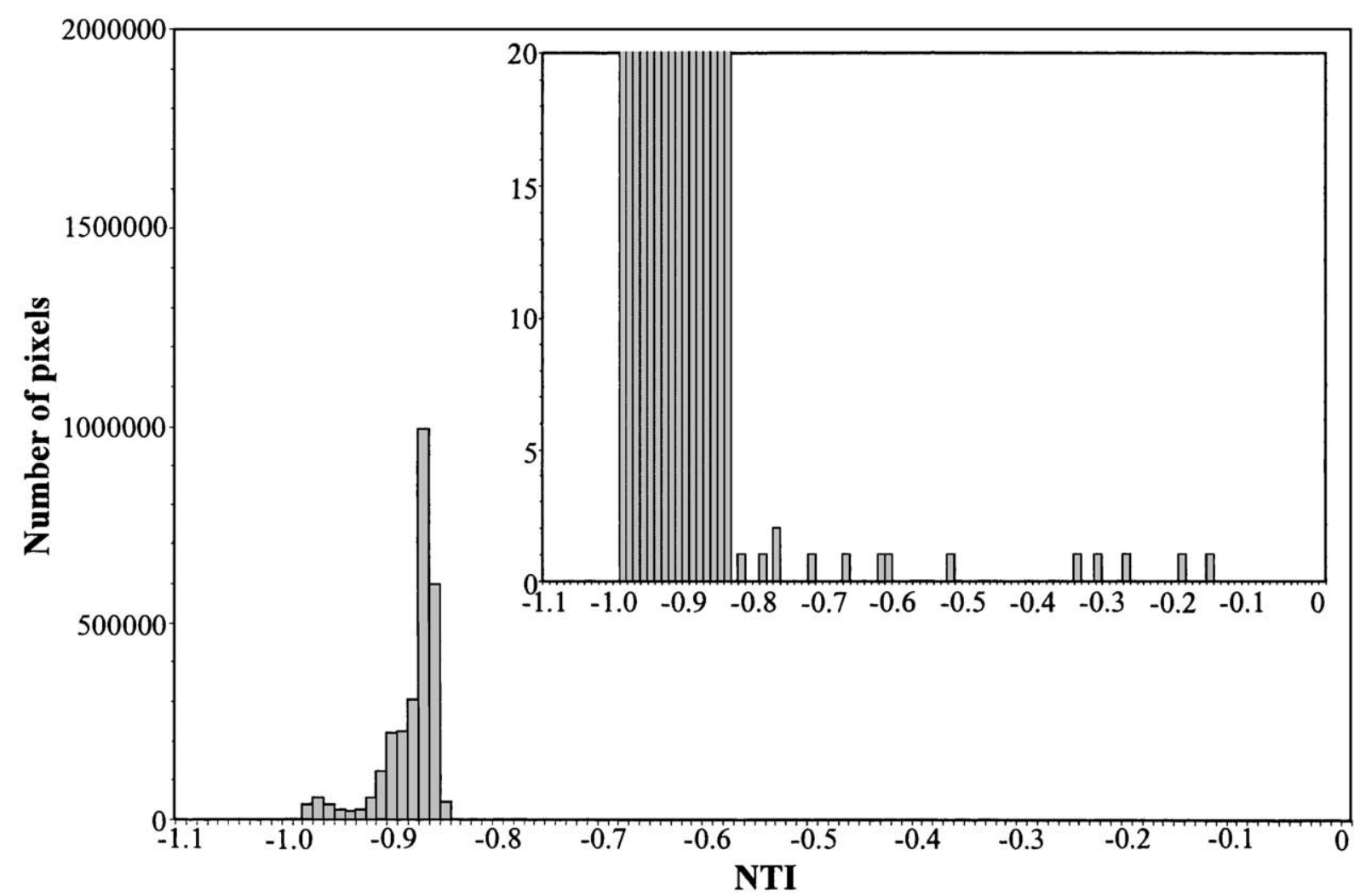

Fig. 7. NTI histogram of all 2748620 pixels in the 2 February 2001 Big Island MODIS data set. The inset shows the same data at a different scale, to highlight the fact that pixels containing active lava form a distinct tail to the NTI distribution. 


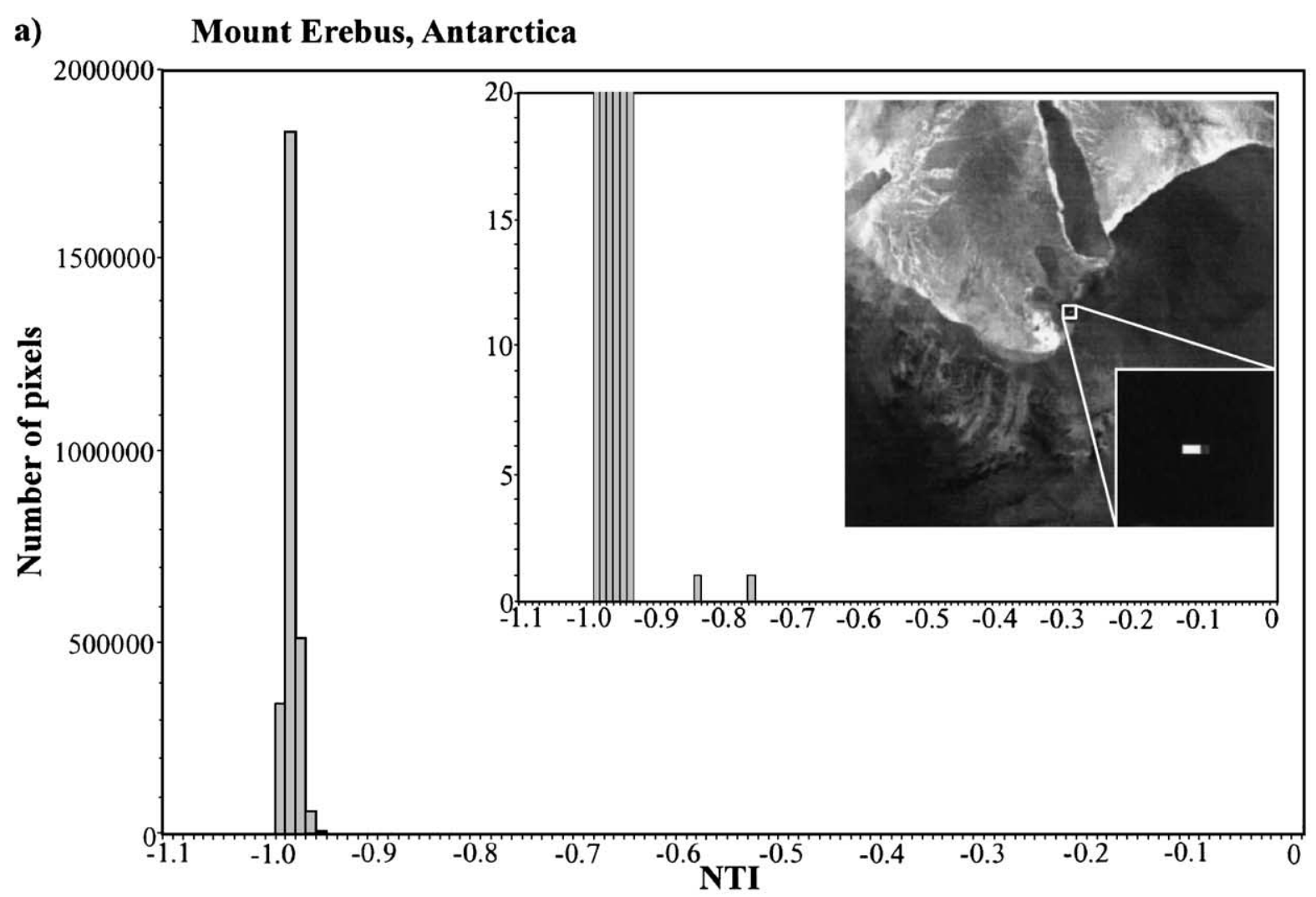

b) Erta Ale, Ethiopia

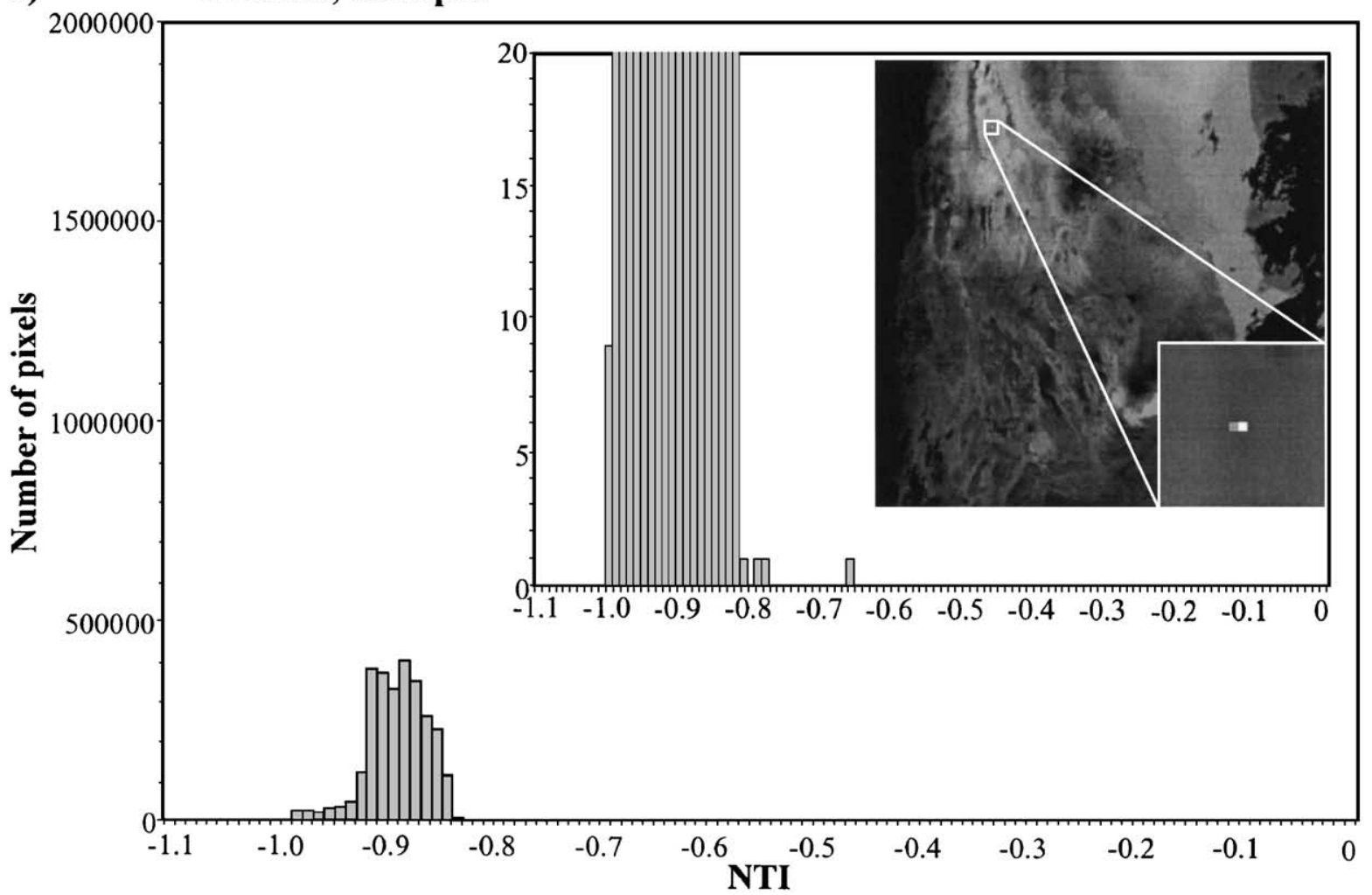

Fig. 8. NTI histograms and Band 22 images derived from nighttime MODIS granules of (a) Mount Erebus (acquired on 1 May 2001), (b) Erta Ale (acquired on 13 November 2000), (c) Etna (acquired on 8 November 2000), and (d) Soufriere Hills (acquired on 23 February 2001). In each case, the right-hand tail of the distribution is composed solely of hotspot pixels. 

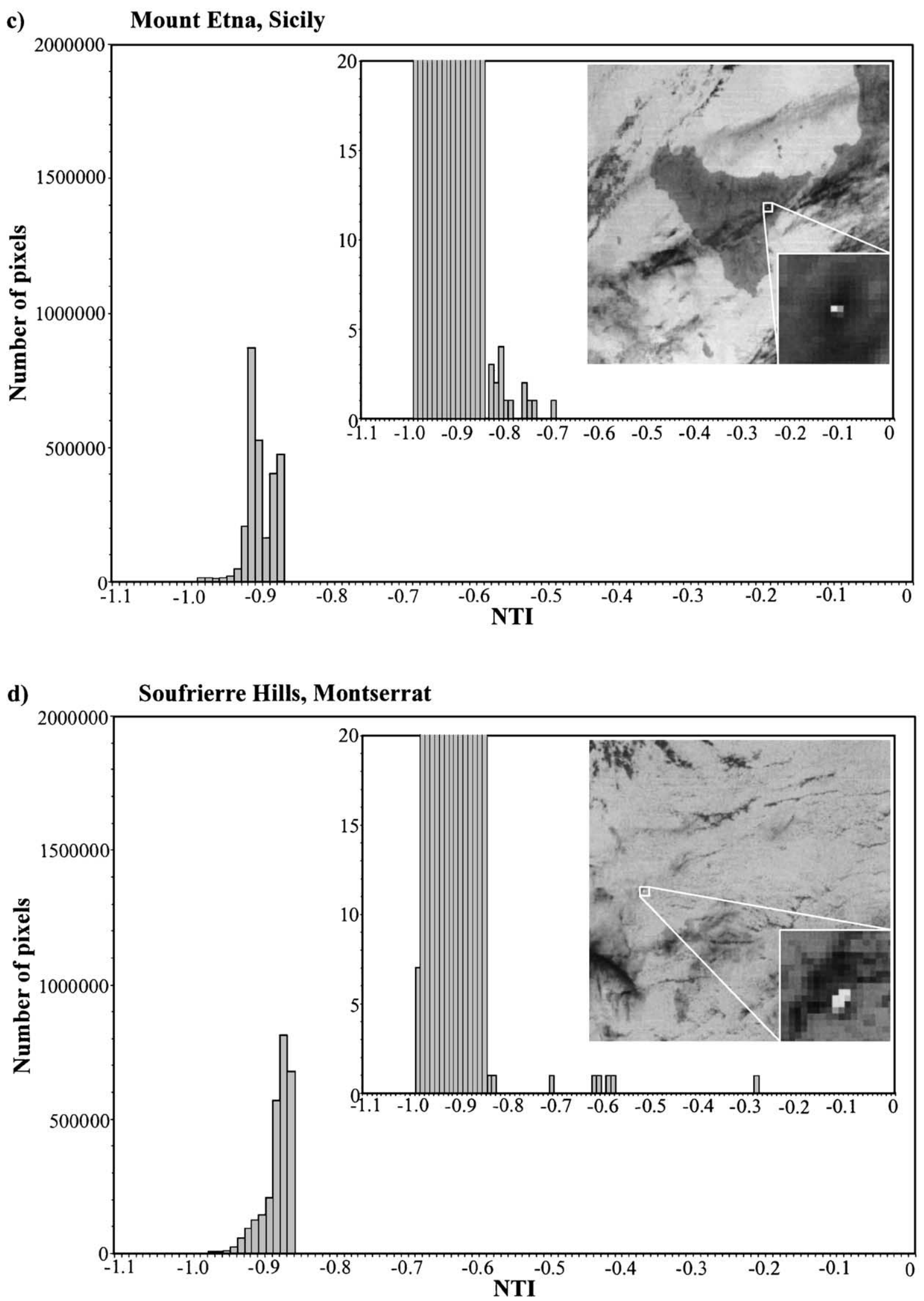

Fig. 8 (continued). 
and Alaska), is inappropriate for volcanoes near the equator, such as Erta Ale, where such a threshold would result in $>100,000$ alerts. In the Big Island data set, where background temperatures (and therefore radiances) are somewhat lower than those characteristic of Ethiopia, a threshold of -0.84 would result in only 44 alerts. However, visual analysis of the image data confirmed that 23 of these would be false. Fig. 8c and d reveals that an NTI threshold of -0.80 would also be appropriate for detecting the hotspots evident at Soufriere Hills, Montserrat (probably hot pyroclastic flows emplaced on and around the 23 March 2001; GVN, 2001a), and the summit crater hotspots at Mount Etna, without encroaching on the main body of the NTI histogram and resulting in false alerts.

Based on the analysis of these and many other MODIS images, we determined an empirical NTI threshold of -0.80 to be appropriate for nighttime global volcanic hotspot detection. Nevertheless, using a single threshold value has implications for the sensitivity of our algorithm to the presence of hotspots in different geographical locations. Fig. 9 provides a simple illustration of this. Here, we have modelled the NTI response of MODIS to a subpixel-sized lava lake, of the kind present at Erta Ale (Case A) and Mount Erebus (Case B). In each case, the curves show how the NTI varies as a function of background temperature, lava lake size, and lava temperature, assuming that the lava lake is composed of a chilled lava crust (radiating at $400{ }^{\circ} \mathrm{C}$ ) within which cracks expose molten lava from the lake interior (radiating at $1000{ }^{\circ} \mathrm{C}$ ). The size of the lake varies between 10 and $10,0000 \mathrm{~m}^{2}$, while the area of high-temperature cracks on the lake surface was allowed to vary between $0.01 \%$ and $100 \%$ of the lake surface itself. Background temperatures were assumed to be 25 and $-35{ }^{\circ} \mathrm{C}$ for Cases $\mathrm{A}$ and $\mathrm{B}$, respectively. These dimensions and temperatures are more than sufficient to cover the range of lava lakes typically observed on Earth (Flynn, Mouginis-Mark, Gradie, \& Lucey, 1993; Harris, Flynn, et al., 1999).

The curves presented in Fig. 9 illustrate how complex the relationship between the value of the NTI and the nature of the radiating surface can be. When the lava lake area is less than $10^{-5}$ of the MODIS $1-\mathrm{km}$ pixel, it is essentially invisible to the sensor, and the NTI approaches an asymptote that corresponds to that of a thermally homogenous surface radiating at $25{ }^{\circ} \mathrm{C}(\mathrm{NTI} \sim-0.86)$ and $-35{ }^{\circ} \mathrm{C}$ (NTI - 0.97) for cases A and B, respectively. As the size of the lava lake increases, the amount of radiance emitted increases at a faster rate at $3.959 \mu \mathrm{m}$ than at $12.02 \mu \mathrm{m}$ (Section 2), MODIS begins to "see" the lake, and the NTI increases as a result. As the 3.959- $\mu \mathrm{m}$ bandwidth is responsive to the subpixel-sized hotspots and the ground that surrounds them, this occurs at a smaller lake size in Case $\mathrm{B}$ than in Case A, where the lake must become larger before it makes itself distinct from the relatively "warm" background. Potentially, therefore, the Case B lava lake could be detected at a smaller size than the Case A lake. However, as discussed in Section 4.1, to do so would require setting an NTI threshold that would be so low as to result in many thousands of false alerts in Case A. Interestingly, Fig. 9 indicates that similar lava lakes in equatorial and polar regions should result in almost the same NTI. However, the results presented in Fig. 9 are difficult to generalise upon as they are entirely model dependent.

Fig. 9 makes an important point: While the NTI index is useful to detect volcanic hotspots, it is not in itself a basis for quantifying the intensity of the hotspot, or as a basis for comparative analysis of geographically disparate volcanoes. Interpreting the absolute NTI value is fraught because of the

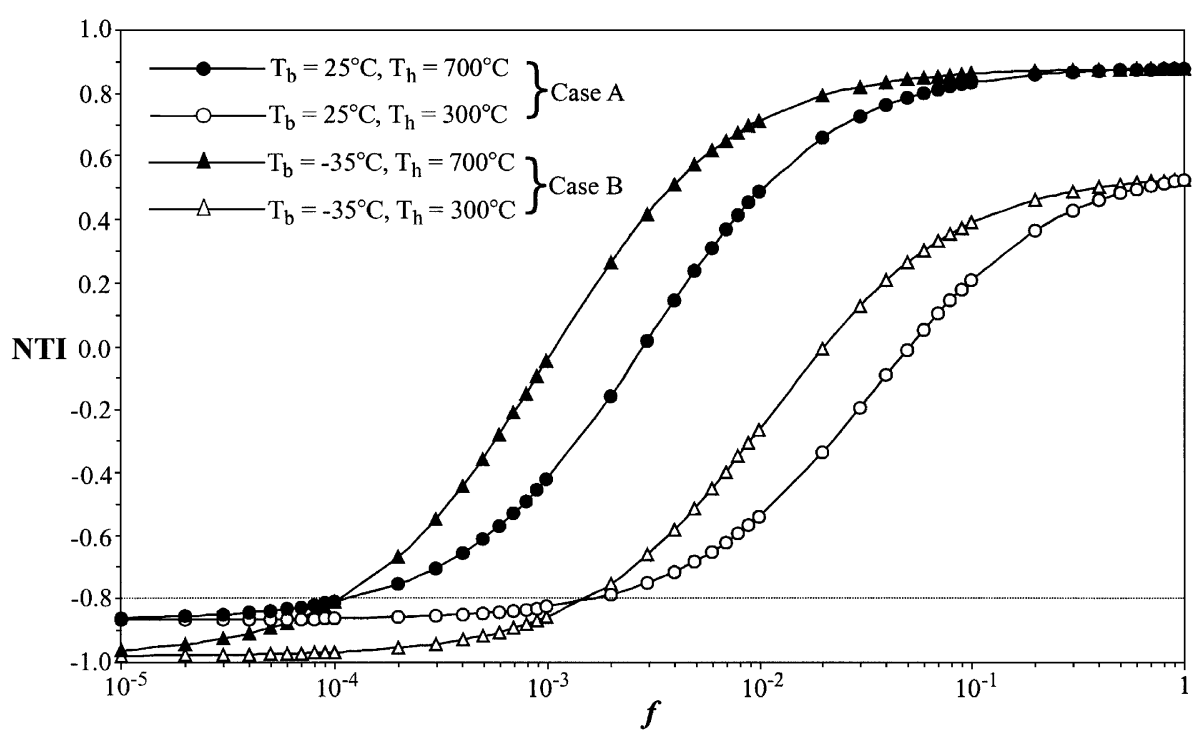

Fig. 9. Modelled variation in the NTI calculated for a pixel containing a subpixel-sized active lava lake. Case A refers to the NTI of a lava lake of the kind that might exist at warm equatorial latitudes (e.g. Erta Ale), while Case B models the NTI response of an identical lava lake at cold Polar latitudes (e.g. Mount Erebus). The horizontal dashed line denotes the empirically determined NTI threshold value of -0.80 , used by the MODVOLC algorithm. 
effect of variations in background temperature on the 3.959and $12.02-\mu \mathrm{m}$ signals, as well as variations in the detailed temperature characteristics of the hotspots themselves. For example, the variations in background temperature that we model in this instance can result in a difference in NTI of $50 \%$ for a given lava lake. Moreover, variations in the composition of the hotspot will also result in large variations in NTI. For example, a $1000-\mathrm{m}^{2}$ Case B lava lake, which was vigorously overturning at the time of MODIS overpass (i.e. the chilled lake surface crust foundering en masse, exposing large areas of molten lava), would be indistinguishable, on the basis of the NTI value, from a $5000-\mathrm{m}^{2}$ Case B lava lake in a state of relative quiescence (i.e. stable crust, relatively few cracks). It is therefore important to bear in mind that while the NTI is a reliable way to automatically detect volcanic hotspots, it should not be used as the basis for quantitative analysis. As we will go on to describe in Section 4.3, there is in fact no need for reliance on the NTI value as an indicator of hotspot intensity, because absolute radiance in Bands 21, 22, 28, 31, and 32 is recorded and reported for each pixel designated as a hotspot by the MODVOLC algorithm.

\subsection{Implementation of the algorithm}

The MODVOLC algorithm has been incorporated into the EOSDIS Core System (ECS), used by NASA's Goddard Earth Science (GES) DAAC to process the MODIS data stream. Fig. 10 illustrates the processing steps diagrammatically. The algorithm uses the MODIS Level 1B data stream. Although MODIS is a 12-bit instrument (i.e. 4096 discrete measurement levels), the Level 1B data are converted from this 12-bit representation to a 16-bit unsigned scaled integer (SI) format (i.e. 0-65535). These unsigned integers are subsequently converted to radiance (in $\mathrm{W} \mathrm{m} \mathrm{m}^{-2} \mathrm{sr}^{-1}$ $\mu \mathrm{m}^{-1}$ ) using calibration parameters stored within each MODIS hierarchical data format (hdf) Level 1B granule.

Although the SI representation allows 65535 measurement levels, only the lower half of the scale (i.e. 0-32767) is used to store science data. SIs in excess of 32767 are designated "reserve values," and are used to indicate various types of "bad" data. For example, a SI of 65531 indicates a dead detector, whereas a value of 65534 indicates that the original Level $1 \mathrm{~A}$ data were missing from the raw MODIS granule. The MODVOLC algorithm identifies bad pixels on the basis of these reserved SI values and excludes them from further processing. Although Bands 22 and 21 were afflicted by dead detectors at launch, they do not occupy the same relative position on the MODIS imaging plane. As a result, Band 22 or 21 data are always available for each of the ten $1-\mathrm{km}$ strips that comprise the MODIS footprint, and no hotspots are missed as a result. The problems caused by dead detectors, electronic crosstalk, and other instrument noises have subsequently been alleviated by a switch from the initial "Side A" to the redundant "Side B" MODIS electronics in November 2000.
The MODVOLC algorithm checks whether a pixel is a daytime or a nighttime pixel by reference to its solar zenith angle (solar zenith, satellite zenith, and satellite azimuth

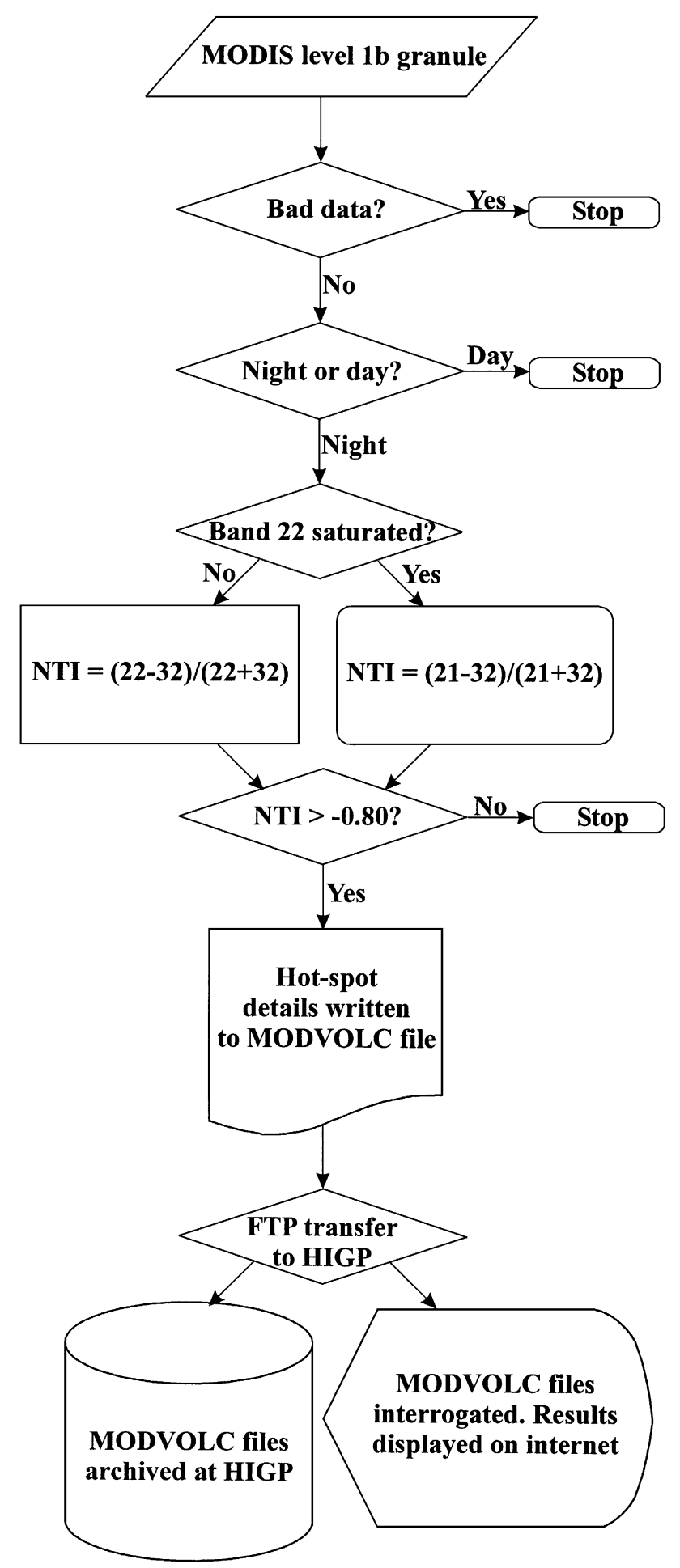

Fig. 10. Flow diagram illustrating the implementation of the MODVOLC algorithm. Hotspot details written to the MODVOLC file include time detected (year/month/day/hour/minute) location (latitude/longitude), spectral radiance in Bands 21, 22, 28, 31, and 32 (in $\mathrm{W} \mathrm{m}^{-2} \mathrm{sr}^{-1} \mu \mathrm{m}^{-1}$ ), satellite zenith, satellite azimuth, and solar zenith (all in degrees). 
are recorded for each pixel in the MODIS granule and stored in the .hdf file). This is done on a pixel-by-pixel basis to account for those situations in which the terminator falls within the 1354-km MODIS swath. This sorting procedure is included in preparation for a daytime version of the MODVOLC algorithm, which is currently under development, and will be implemented as soon as computer processing resources at the GSFC DAAC permit. If the pixel is a nighttime pixel, the algorithm establishes whether it is saturated in Band 22. This is done, again, on the basis of a SI value reserved for detector saturation $(\mathrm{SI}=65533$ ). If Band 22 is unsaturated, the NTI is calculated using Bands 22 and 32. If Band 22 is saturated, the NTI is calculated using Bands 21 and 32 . The value is then compared against the empirically determined NTI threshold value of -0.80 . Pixels with NTI $>-0.80$ are considered as hotspots, and the details are written to an ASCII text file given the GSFC Earth Science Data Type name "MODVOLC." For each hotspot pixel, the MODVOLC file records the time when it was detected (year/ month/day/hour/minute), its location (latitude/longitude), spectral radiance in Bands 21, 22, 28, 31, and 32 (in W $\left.\mathrm{m}^{-2} \mathrm{sr}^{-1} \mu \mathrm{m}^{-1}\right)$, satellite zenith, satellite azimuth, and solar zenith (all in degrees).

The MODVOLC files are transferred via file transfer protocol (FTP) to HIGP, University of Hawaii, where the results are displayed on the Internet (http://modis.higp.hawaii.edu). The front page of the website provides a global view of all hotspots detected during the previous 24-h period and can be interrogated at larger scales for the incidence of hotspots at individual volcanoes. The appearance and functionality of the site are constantly being developed and improved. However, all revisions allow the data contained in the original MODVOLC files to be easily retrieved, and allow quick access to the MODVOLC hotspot data archive.

\section{Results}

\subsection{Volcanic hotspots}

MODVOLC has detected hotspots (Table 1) associated with a wide range of eruptive styles at 33 different volca-

Table 1

Volcanoes that have been identified as "hotspots" by MODVOLC and the number of times they have been detected for the periods 1 October 2000 to 30 November 2000 and 1 February 2001 to 31 May 2001

\begin{tabular}{|c|c|c|c|}
\hline Volcano name (location) & Latitude/Longitude & MODVOLC alerts & Nature of activity \\
\hline Ambrym (Vanuata) & $16.25^{\circ} \mathrm{S}, 168.12^{\circ} \mathrm{E}$ & 8 & Lava lake \\
\hline Arenal (Costa Rica) & $10.46^{\circ} \mathrm{N}, 84.70^{\circ} \mathrm{W}$ & 1 & Vent activity \\
\hline Bagana (Papua New Guinea) & $6.14^{\circ} \mathrm{S}, 155.19^{\circ} \mathrm{E}$ & 10 & Lava dome \\
\hline Bezymianny (Russia) & $55.98^{\circ} \mathrm{N}, 160.59^{\circ} \mathrm{E}$ & 10 & Lava dome/pyroclastic flow \\
\hline Big Ben (Heard Island) & $53.10^{\circ} \mathrm{S}, 73.51^{\circ} \mathrm{E}$ & 5 & Vent activity/lava flows \\
\hline Cleveland (Aleutian Islands) & $52.82^{\circ} \mathrm{N}, 169.95^{\circ} \mathrm{W}$ & 3 & Vent activity \\
\hline Erebus (Antarctica) & $77.53^{\circ} \mathrm{S}, 167.17^{\circ} \mathrm{E}$ & 58 & Lava lake \\
\hline Erta Ale (Ethiopia) & $13.60^{\circ} \mathrm{N}, 40.67^{\circ} \mathrm{E}$ & 49 & Lava lake \\
\hline Etna (Sicily) & $37.73^{\circ} \mathrm{N}, 15.00^{\circ} \mathrm{E}$ & 63 & Vent activity, lava flows \\
\hline Ibu (Halmahera) & $1.48^{\circ} \mathrm{N}, 127.63^{\circ} \mathrm{E}$ & 2 & Vent activity \\
\hline Karangetang (Siau Islands) & $2.47^{\circ} \mathrm{N}, 125.29^{\circ} \mathrm{E}$ & 10 & Lava dome \\
\hline Kilauea (Hawaii) & $19.42^{\circ} \mathrm{N}, 155.29^{\circ} \mathrm{W}$ & 87 & Lava flows \\
\hline Láscar (Chile) & $23.37^{\circ} \mathrm{S}, 67.73^{\circ} \mathrm{W}$ & 4 & Lava dome \\
\hline Lopevi (Vanuata) & $16.50^{\circ} \mathrm{S}, 168.34^{\circ} \mathrm{E}$ & 1 & Lava flows/vent activity \\
\hline Mayon (Philippines) & $13.25^{\circ} \mathrm{N}, 123.68^{\circ} \mathrm{E}$ & 2 & Lava dome \\
\hline Merapi (Java) & $07.54^{\circ} \mathrm{S}, 110.44^{\circ} \mathrm{E}$ & 20 & Lava dome/pyroclastic flow \\
\hline Michael (South Sandwich Islands) & $57.78 \mathrm{~S}, 26.45 \mathrm{~W}$ & 2 & Unknown \\
\hline Miyake-jima (Japan) & $34.08^{\circ} \mathrm{N}, 139.53^{\circ} \mathrm{E}$ & 1 & Vent activity \\
\hline Nyamuragira (Zaire) & $1.40^{\circ} \mathrm{S}, 29.20^{\circ} \mathrm{E}$ & 18 & Lava flows \\
\hline Pacaya (Guatemala) & $14.38^{\circ} \mathrm{N}, 90.60^{\circ} \mathrm{W}$ & 1 & Vent activity \\
\hline Piton de la Fournaise (Réunion Island) & $21.23^{\circ} \mathrm{S}, 55.71^{\circ} \mathrm{E}$ & 21 & Lava flows \\
\hline Popocatépetl (Mexico) & $19.02^{\circ} \mathrm{N}, 98.62^{\circ} \mathrm{W}$ & 38 & Lava dome \\
\hline Rabaul (Papua New Guinea) & $4.27^{\circ} \mathrm{S}, 152.20^{\circ} \mathrm{E}$ & 3 & Vent activity \\
\hline Santa Maria (Guatemala) & $14.75^{\circ} \mathrm{N}, 91.55^{\circ} \mathrm{W}$ & 39 & Lava dome, block lava flow \\
\hline Semeru (Java) & $8.11^{\circ} \mathrm{N}, 112.92^{\circ} \mathrm{E}$ & 14 & Vent activity \\
\hline Shiveluch (Russia) & $56.65^{\circ} \mathrm{N}, 161.36^{\circ} \mathrm{E}$ & 13 & Lava dome/pyroclastic flow \\
\hline Soufriere Hills (Montserrat) & $16.72^{\circ} \mathrm{N}, 62.18^{\circ} \mathrm{W}$ & 28 & Lava dome/pryoclastic flow \\
\hline Stromboli (Italy) & $38.79^{\circ} \mathrm{N}, 15.21^{\circ} \mathrm{E}$ & 1 & Vent activity \\
\hline Tinakula (Santa Cruz Islands) & $10.38^{\circ} \mathrm{S}, 165.80^{\circ} \mathrm{E}$ & 3 & Vent activity/lava flows \\
\hline Tofua (Tonga) & $19.75^{\circ} \mathrm{S}, 175.07^{\circ} \mathrm{W}$ & 1 & Caldera \\
\hline Ulawun (Papua New Guinea) & $5.04^{\circ} \mathrm{S}, 151.34^{\circ} \mathrm{E}$ & 3 & Lava flows \\
\hline Villarrica (Chile) & $39.42^{\circ} \mathrm{S}, 71.93^{\circ} \mathrm{W}$ & 1 & Lava lake \\
\hline Yasur (Vanuatu) & $19.52^{\circ} \mathrm{S}, 169.43^{\circ} \mathrm{E}$ & 2 & Vent activity \\
\hline
\end{tabular}


noes worldwide since October 2000 (Flynn et al., 2002 provide a summary of some of these results). In this section, we review some of these results to illustrate the utility of the
MODVOLC algorithm for monitoring global volcanism. As noted in a previous section, gaps between adjacent MODIS swaths occur close to the equator, reducing the frequency of
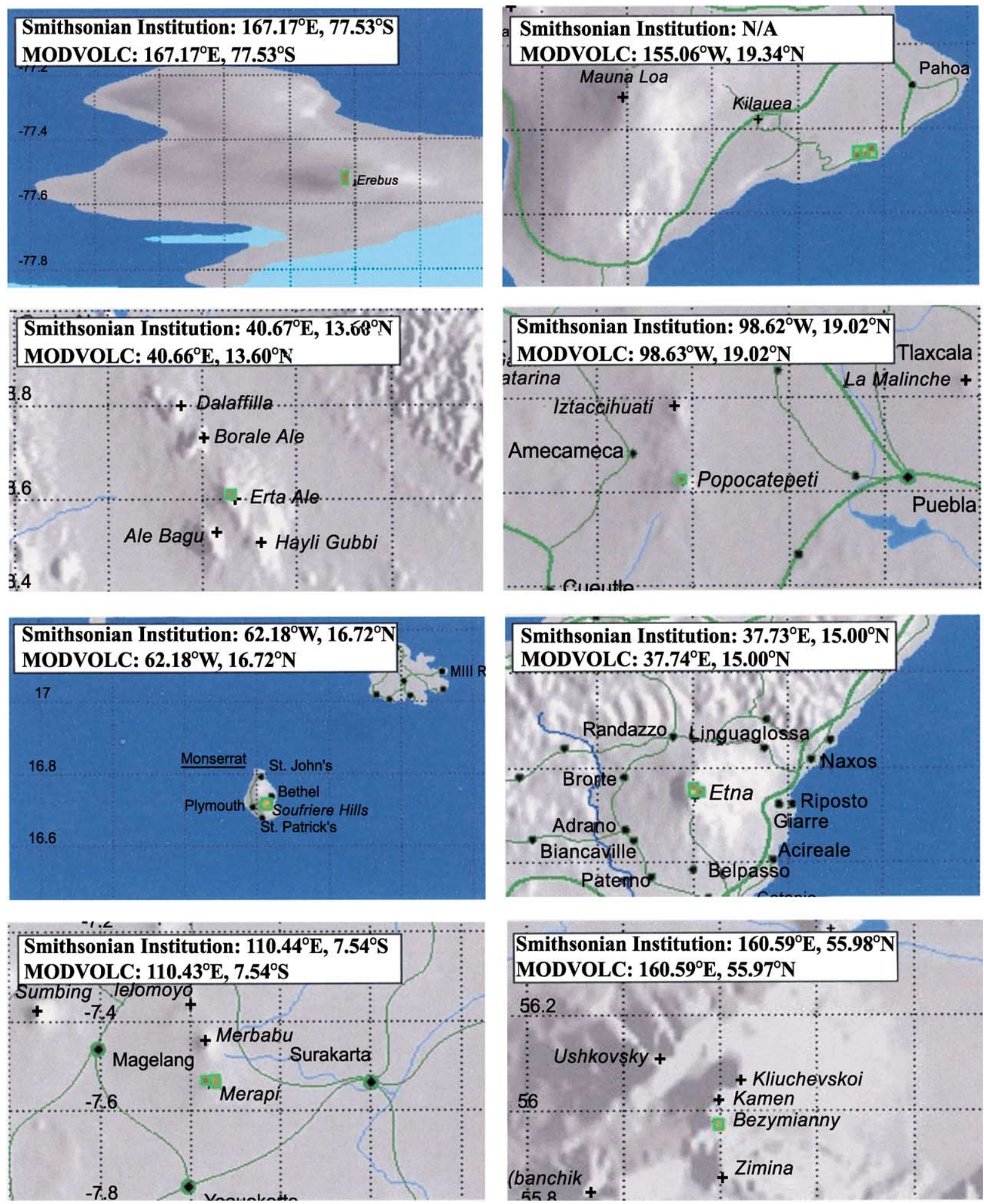

Fig. 11. Image maps taken from the MODVOLC website (http://modis.higp.hawaii.edu) showing hotspots (green dots) detected by the MODVOLC algorithm at (left to right, top to bottom); Erebus, Kilauea, Erta Ale, Popocatépetl, Soufriere Hills, Mount Etna, Merapi, and Bezymianny. The location of each hotspot as reported by MODVOLC is shown alongside the published location (Simkin \& Seibert, 1994) for comparison. Dashed boxes are $5^{\circ}$ in latitude and longitude. The MODVOLC hotspots have a colour gradation, with green-yellow-red indicating increasing intensity of the 3.959- $\mu \mathrm{m}$ emitted radiance. 
Table 2

Location of the hotspots detected at Erta Ale by the MODVOLC algorithm during February 2001. Simkin and Siebert (1994) report a location of $40.67^{\circ} \mathrm{E}, 13.60^{\circ} \mathrm{N}$ for Erta Ale's summit caldera, within which these hotspots lie

\begin{tabular}{ll}
\hline Date & $\begin{array}{l}\text { MODVOLC hotspot location } \\
\text { (latitude/longitude) }\end{array}$ \\
\hline 2 February 2001 & $40.653^{\circ} \mathrm{E}, 13.605^{\circ} \mathrm{N}$ \\
4 February 2001 & $40.659^{\circ} \mathrm{E}, 13.604^{\circ} \mathrm{N}$ \\
8 February 2001 & $40.662^{\circ} \mathrm{E}, 13.601^{\circ} \mathrm{N}$ \\
13 February 2001 & $40.661^{\circ} \mathrm{E}, 13.603^{\circ} \mathrm{N}$ \\
15 February 2001 & $40.660^{\circ} \mathrm{E}, 13.601^{\circ} \mathrm{N}$ \\
17 February 2001 & $40.660^{\circ} \mathrm{E}, 13.600^{\circ} \mathrm{N}$ \\
19 February 2001 & $40.663^{\circ} \mathrm{E}, 13.602^{\circ} \mathrm{N}$ \\
22 February 2001 & $40.659^{\circ} \mathrm{E}, 13.600^{\circ} \mathrm{N}$ \\
24 February 2001 & $40.660^{\circ} \mathrm{E}, 13.602^{\circ} \mathrm{N}$ \\
\hline
\end{tabular}

data collection for volcanoes at these latitudes. Cloud cover also prevents detection of volcanic thermal anomalies. However, in spite of these sampling limitations MODVOLC has reliably detected hotspots at both permanently and sporadically active volcanoes. As noted in Section 2, the MODVOLC algorithm detects hotspots, but it does not discriminate the nature of the hotspot. As a result, their interpretation can be fraught with difficulty, as the spectral signature of biomass burning could be mistaken for eruptive activity. Accurate location of where the hotspots occur therefore becomes critical for determining the cause of the anomaly. The accuracy of the MODIS Level 1B geolocation $(\sim 200 \mathrm{~m})$ provides a valuable means for assessing the veracity and reliability of the MODVOLC algorithm, as we can confidently compare MODVOLC detected hotspot locations to the positions of known volcanic activity. Fig. 11 presents maps compiled from the MODVOLC website showing detected hotspots for a range of volcanoes. For comparison, the latitude and longitude of the hotspot as recorded by MODVOLC is shown alongside the coordinates of the summit of the volcano as published by Simkin and Seibert (1994).

Persistently active lava lakes are known to have existed at Erta Ale (Ethiopia) and Mount Erebus (Antarctica) for at least 200 years, although ground observations are rare because of their geographical isolation (Harris, Wright, \& Flynn, 1999; Tazieff, 1994). MODVOLC regularly detects the hotspots associated with these lava lakes (Fig. 11; Table 1). The lakes in question are significantly smaller than the 1$\mathrm{km}$ MODIS pixel size and, as a result, only one or two hotspot pixels are detected by MODIS at these volcanoes. Table 2 shows the locations reported for hotspots observed at Erta Ale during February 2001. The accuracy is clearly good enough to be confident that the hotspots are volcanic in origin.

Spatially extensive lava flows are an almost permanent characteristic of the ongoing eruption at Kilauea Volcano in
Hawaii, a fact reflected in the large number of alerts reported by MODVOLC for this volcano (87 between 1 October 2000 to 30 November 2000, and 1 February 2001 to 31 May 2001). The hotspots observed to date have all been sited close to the coast, several kilometers southeast of the current active vent (at Pu'u 'O'o). This is entirely consistent with the nature of the activity at the time of image acquisition, whereby surface pahoehoe lava flows fed by tubes extending from the vicinity of Pu'u 'O'o are often most abundant on the coastal plain.

Mount Etna is the largest and most active volcano in Europe with a documented history of eruptions stretching back almost 2000 years (Chester, Duncan, Guest, \& Kilburn, 1985). Given this level of activity, it is not surprising that MODVOLC regularly detects hotspots at its summit. Historically, eruptions at Etna can be divided into two main groups: those that initiate within its summit crater region, and those that begin at flank vents on the lower slopes of the edifice (Chester et al., 1985). The ability of MODVOLC to locate hotspot pixels to an accuracy of $\sim 200 \mathrm{~m}$ will therefore prove valuable in determining whether detected hotspots are associated with the former or the latter. In the example presented in Fig. 11, the hotspot is clearly confined to the summit region when, consistent with field reports describing the predominance of high-temperature Strombolian explosions within the Bocca Nuova, one of four active craters at Etna's summit at this time (GVN, 2001b).

Since eruptive activity began in 1995, Soufriere Hills Volcano has devastated the southern sector of the tiny Caribbean Island of Montserrat. The volcanic threat is posed by the intermittent collapse or explosive disruption of a lava dome growing at the volcano's summit, which results in pyroclastic flows sweeping down valleys on the flanks of the volcano (Young et al., 1998). On 23 February 2001, MODVOLC detected six hotspot pixels at Soufriere Hills Volcano (Figs. 8d and 11). Although the growing lava dome is much smaller than a single $1-\mathrm{km}$ MODIS pixel, this relatively large number of hotspots is easily reconciled with reference to field reports that describe the emplacement of extensive pyroclastic flows on and around the 23 February eruption (GVN, 2001a).

The previous discussion has illustrated the value of MODVOLC as a hotspot detection tool. We now recount three case studies that show how MODVOLC can be used to monitor the onset, development and cessation of discrete eruptive events. We do this using case studies taken from eruptions at Nyamuragira, Shivulech, and Piton de la Fournaise.

\subsubsection{Nyamuragira}

Nyamuragira is situated on the border between Rwanda and the Democratic Republic of Congo. On 6 February

Fig. 12. Top: The total amount of spectral radiance detected by MODVOLC (i.e. summed for all pixels identified as hotspots by the algorithm) during the February to March 2001 eruption of Nyamurgira, Democratic Republic of Congo. Bottom: Image maps taken from the MODVOLC website showing the distribution of the detected hotspots, with a field map of the location of the lava flows responsible for comparison (map adapted from GVN, 2001c). 

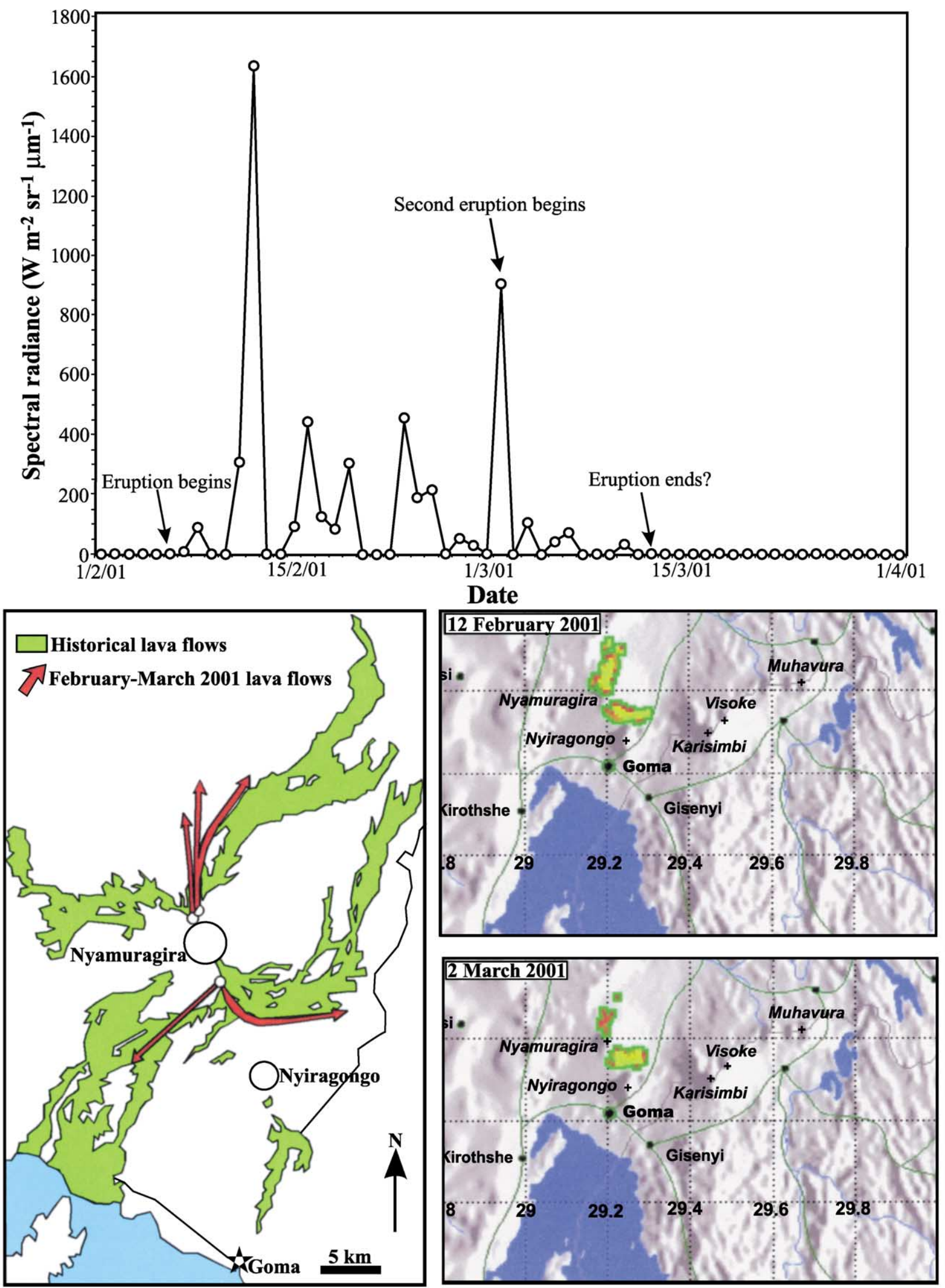
2001, a large eruption began, which lasted until mid-March 2001, during which time lava flows were erupted extending $10-20 \mathrm{~km}$ along the south and west flanks of the volcano (GVN, 2001c). Direct field observations are difficult because the area is held by the rebel group "Congo Rally for Democracy." As a result, MODVOLC provided an important chronology of the spatial and temporal development of the eruption (GVN, 2001d). Fig. 12 shows how the total amount of radiance emitted at $3.959 \mu \mathrm{m}$, as reported by the MODVOLC algorithm, varied over the duration of the eruption. Field reports indicate that the eruption began on 6 February 2001 with the opening of two fissures on the north and south flanks of the volcano. The northern vent erupted flows that extended $15-20 \mathrm{~km}$ due north of the volcano, while the southern vent erupted flows that extended a similar distance to the southwest. The amount of radiance detected by MODVOLC rises quickly to a peak within several days of the beginning of the eruption and then falls by almost an order of magnitude. This is consistent with the common tendency of large effusive eruptions to exhibit rapidly increasing levels of lava production during the early stages of the eruption (a short "waxing" phase; Wadge, 1981) before reverting to a much longer phase of exponentially decreasing lava production (a long "waning" phase; Harris, Murray, et al., 2000). However, the waning phase is interrupted by a second sharp rise in emitted radiance detected by MODVOLC on 2 March. Field reports indicate that a new eruption that began on Nyamuragira's southern flank on the 2 March 2001 (GVN, 2001c), thus explaining this perhaps unexpected radiance increase. Although we have no ground confirmation regarding when the eruption ended, MODVOLC reports a decreasing radiance trend over the first half of March, with the last hotspot recorded on 13 March 2001. This is consistent with fields reports that describe how the intensity of the lava flows decreased in mid-March (GVN, 2001c).

Fig. 12 also shows field maps of the location of the lava flows produced during this eruption (GVN, 2001c) alongside two hotspot maps taken from the MODVOLC website. Although the MODVOLC algorithm reliably documents the relative position and dimensions of the two major flows to the north and east of the volcano, a third flow to the southwest goes unrecorded. Field reports (GVN, 2001c) show that the majority of the ash erupted during the episode was deposited to the southwest of the volcano, exactly coincident with the location of this undetected flow. It is likely that the cloud that transported this ash obscured the flow from MODIS, thus preventing its detection by MOD-
VOLC. This illustrates a significant limitation of our algorithm. Without the original image data or, as in this instance, reliable field observations, it is impossible to know how the presence of meteorological or volcanic ash clouds hinders the detection process. This poses problems when interpreting MODVOLC radiance time series as a short-term decrease in detected hotspot radiance may not necessarily be due to changes in the intensity of the volcanic activity.

\subsubsection{Shiveluch}

Shivulech is one of Kamchatka's largest and most active volcanoes, with a long history of dome growth events and explosive eruptions. From relatively low levels in January and February 2001, activity increased during April 2001, and a sharp increase in seismicity prompted the Kamchatka Volcanic Eruptions Response Team (KVERT) to increase the hazard status of the volcano on 24 April 2001 (GVN, 2001e). MODVOLC reported hotspot activity on 30 April (Fig. 13, confirmed by manual analysis of AVHRR data by AVO scientists; GVN, 2001e). MODVOLC reports a strong increase in the intensity of hotspot activity on 1 May. This thermal anomaly preceded intense seismic tremor on 7 May, believed to have been caused by the growth of a new lava dome (GVN, 2001e). On 19 May 2001, at 04:46 GMT, Shiveluch erupted explosively for $40 \mathrm{~min}$, producing a 10 $\mathrm{km}$-high ash cloud and emplacing pyroclastic flows and hot avalanches in the immediate vicinity of the active dome. The radiance peak detected by MODVOLC some $7 \mathrm{~h}$ later (point iv on Fig. 13) almost certainly relates to the emplacement of these hot pyroclastic flows.

\subsubsection{Piton de la Fournaise}

Piton de la Fournaise is a basaltic shield volcano that forms the southeastern half of Réunion Island, $700 \mathrm{~km}$ east of Madagascar. It is one of the most active oceanic volcanoes in the world, having erupted more than 100 times in the last 300 years $(\mathrm{GVN}, 2001 \mathrm{f})$. Increasing volcanic tremor culminated in a lava eruption on 27 March 2001 from a fissure on the southeastern flank of the volcano $(\mathrm{GVN}$, 2001f). MODVOLC immediately detected the hotspots associated with the onset of the eruption (Fig. 13). The hotspot alignment MODVOLC reports (inset, Fig. 13) is clearly consistent with the reported direction of the flows, which extended along the southeastern flank of the volcano (GVN, 2001f). The eruption ended on 4 April 2001 (GVN, 2001f). MODVOLC records a declining trend in emitted radiance between 30 March and 2 April. No hotspots were detected by MODVOLC after this time.

\footnotetext{
Fig. 13. Top: The total amount of spectral radiance detected by MODVOLC (i.e. summed for all pixels identified as hotspots by the algorithm) during the April-May 2001 eruption of Shiveluch, Russia. Image maps taken from the MODVOLC website showing the spatial location of the detected hotspots are also included. Images i, ii, iii, and iv were acquired on dates corresponding to points i, ii, iii, and iv on the adjacent graph. Bottom: The total amount of spectral radiance detected by MODVOLC (i.e. summed for all pixels identified as hotspots by the algorithm) during the March 2001 eruption of Piton de la Fournaise, Réunion Island. The inset shows an image map taken from the MODVOLC website on 28 March 2001. The orientation of the hotspot is clearly consistent with reported east-south-east direction of the lava flows.
} 

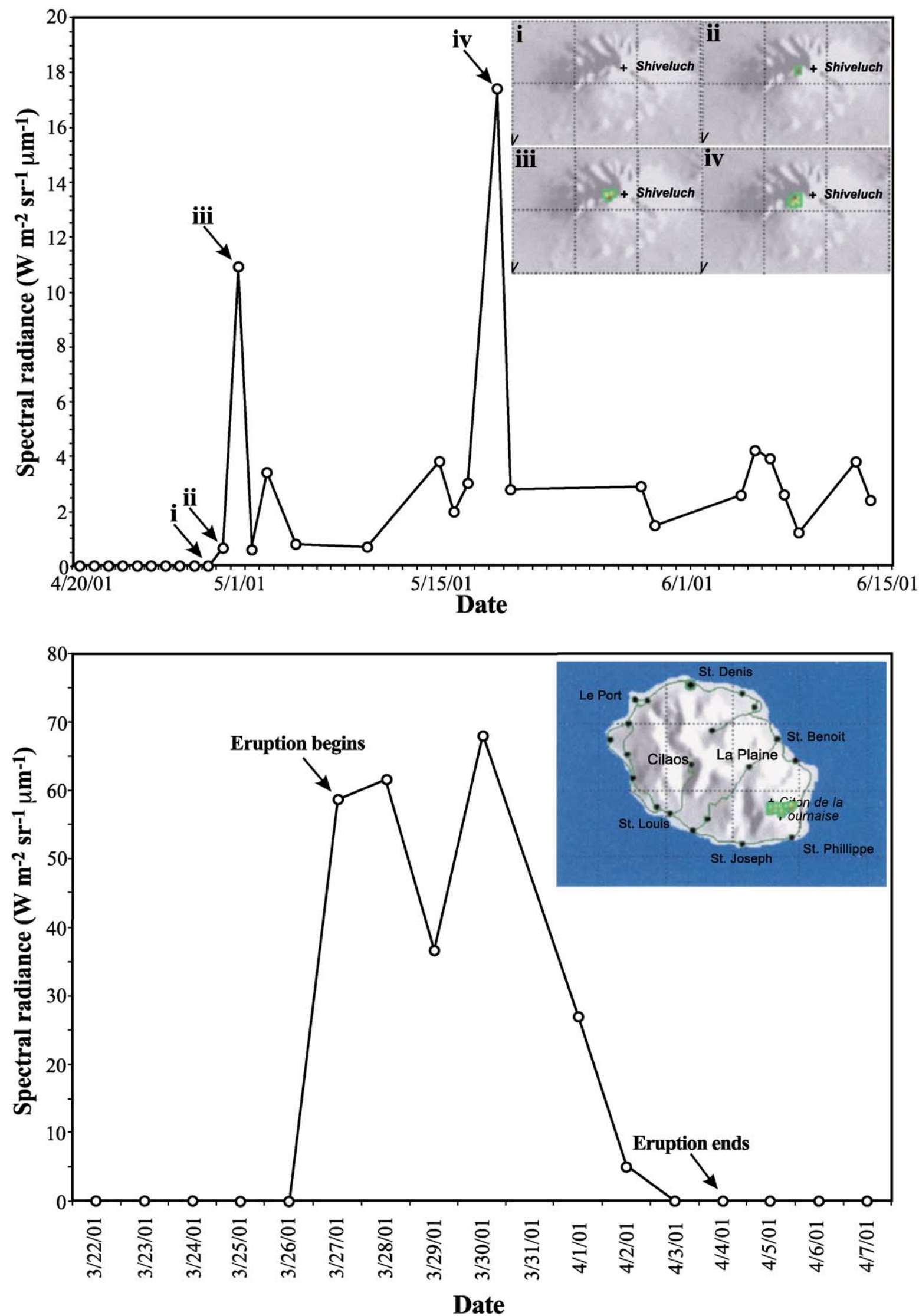


\subsection{Further applications: wildfires and industrial hotspots}

The MODIS Fire Team have developed a complex algorithm to detect, monitor, and characterise wildfires in order to quantify pyrogenic trace gas and aerosol emissions during biomass burning events (Kaufman et al., 1998). Although the MODVOLC algorithm was primarily intended as a means for rapid detection of volcanic eruptions, it can also be used to detect wildfires and establish how their distribution changes through time. Fig. 14a shows all hotspots detected by MODVOLC during October 2001. Although vegetation fires occur all over the planet, there are certain areas where they are particularly frequent and intense, with $80 \%$ of forest fires occurring within the tropics. The distribution of hotspots detected by MODVOLC reflects this pattern, with high concentrations occurring in the savanna regions of central Africa, Central America, the Orinoco and Amazonia Basins of South America, coastal regions of Australia and Southeast Asia. These are all fire-prone regions traditionally associated with high incidences of satellite-detected hotspots. Fig. 14b and c shows hotspots detected by MODVOLC over South America on 23 March and 7 June 2001. Wildfires detected by the Brazilian National Institute for Space Research (INPE) using AVHRR data on the same day are shown for comparison. Although there are differences, the fire distribution detected by MODVOLC bears close resemblance to that reported by INPE, in particular, the shift in the main burning zone from the Orinoco basin (Venezuela and Colombia) in March 2001 to the Amazon basin (Brazil) in June 2001. Although we do not attempt a thorough crossvalidation of the relative accuracy of the two products, it appears that MODVOLC can be used to monitor the spatial and temporal distribution of wildfires.

MODVOLC has also proven itself capable of identifying a range of persistent industrial hotspots, especially gas and oil flares. Fig. $14 \mathrm{~d}-\mathrm{g}$ provides a range of examples. Hotspots are routinely detected by MODVOLC in the Campos Basin off the coast of Brazil (United States Geological Survey Geological Province Code No. 6035; Klett, Ahlbrandt, Schmoker, \& Dolton, 1997), the Villahermosa Uplift (Gulf of Mexico; No. 5305), the Rub Al Khali basin (Persian Gulf; No. 2019), and the Niger Delta (No. 7192), amongst others.

\subsection{Validation and limitations of the algorithm}

It is difficult to validate the accuracy, for example, of each of the wildfire hotspots presented in the previous section, although they are clearly consistent with distributions determined independently (Fig. 14b,c). A notable exception is Rothery, Thorne, and Flynn (in press), which provides detailed ground validation (Table 1, therein) of MODVOLC hotspots observed in Britain over a 6-month period at the beginning of 2001 , attributable to sources as diverse as petrochemical factories, steel works, warehouse fires, and "foot-and-mouth" pyres. Our confidence in the performance and stability of the MODVOLC algorithm is further supported by several sources of evidence. Firstly, hotspots detected for volcanoes such as Erta Ale, Erebus, and Popocatépetl (where the source of radiance is known to be contained within a relatively small and spatially invariant summit crater) consistently fall within a few seconds of arc of the accepted location of the summits. Secondly, spatially extensive contiguous hotspots, such as those detected at Nyamuragira and Piton de la Fournaise, have dimensions and orientations wholly consistent with field-based observations. Thirdly, although every granule for the entire globe is subjected to the MODVOLC algorithm, we only get hotspots in areas where we expect to see them. That there are few, if any, alerts in regions that we do not expect to contain hotspots (i.e. oceans, uninhabited polar regions) while consistently detecting large numbers of hotspots in areas where we do expect to find them (e.g. South America, central Africa, Australia) indicates that the algorithm is both efficient and stable.

Although the MODVOLC algorithm appears to provide a robust tool for detecting hotspots at the global scale, there are several limitations that should be addressed. The first is that the algorithm does not detect all thermally anomalous pixels associated with a particular anomaly. For example, manual inspection of the Big Island MODIS data set depicted in Fig. 3 showed that although 21 pixels were thermally anomalous with respect to the surrounding background, MODVOLC only classified 13 as hotspots. This problem is common to all automatic hotspot monitoring methodologies and stems from a desire to eliminate false alerts by setting relatively high threshold values. However, the effect is compounded by the sampling regime of the MODIS sensor. It is likely that the radiance from any hotspot will be shared between two adjacent pixels (Fig. 1 ), and this dilution can result in only one of the two pixels exceeding the NTI threshold or, in certain cases, the hotspot not being detected at all. We must stress, however, that the MODVOLC algorithm serves merely to facilitate rapid detection of hotspots, and for this purpose, it is not necessary to detect all thermally anomalous pixels associated with a given thermal anomaly. Although the algorithm returns

Fig. 14. (a) Composite image showing all hotspots detected by MODVOLC during October 2001. (b and c) Wildfires (green dots) detected by MODVOLC in South America on (b) 27 March and (c) 7 June 2001. Wildfires (red dots) detected by INPE using AVHRR data on the same day are shown for comparison (Source, INPE-DSA). (d-g) Hotspots associated with gas and oil flares detected by MODVOLC during February 2001 at: Campos Basin off the coast of Brazil, the Villahermosa Uplift in the Gulf of Mexico, the Rub Al Khali basin in the Persian Gulf, and the Niger Delta off the coast of West Africa, respectively. Each dashed box measures $5^{\circ}$ in both latitude and longitude. 
a)

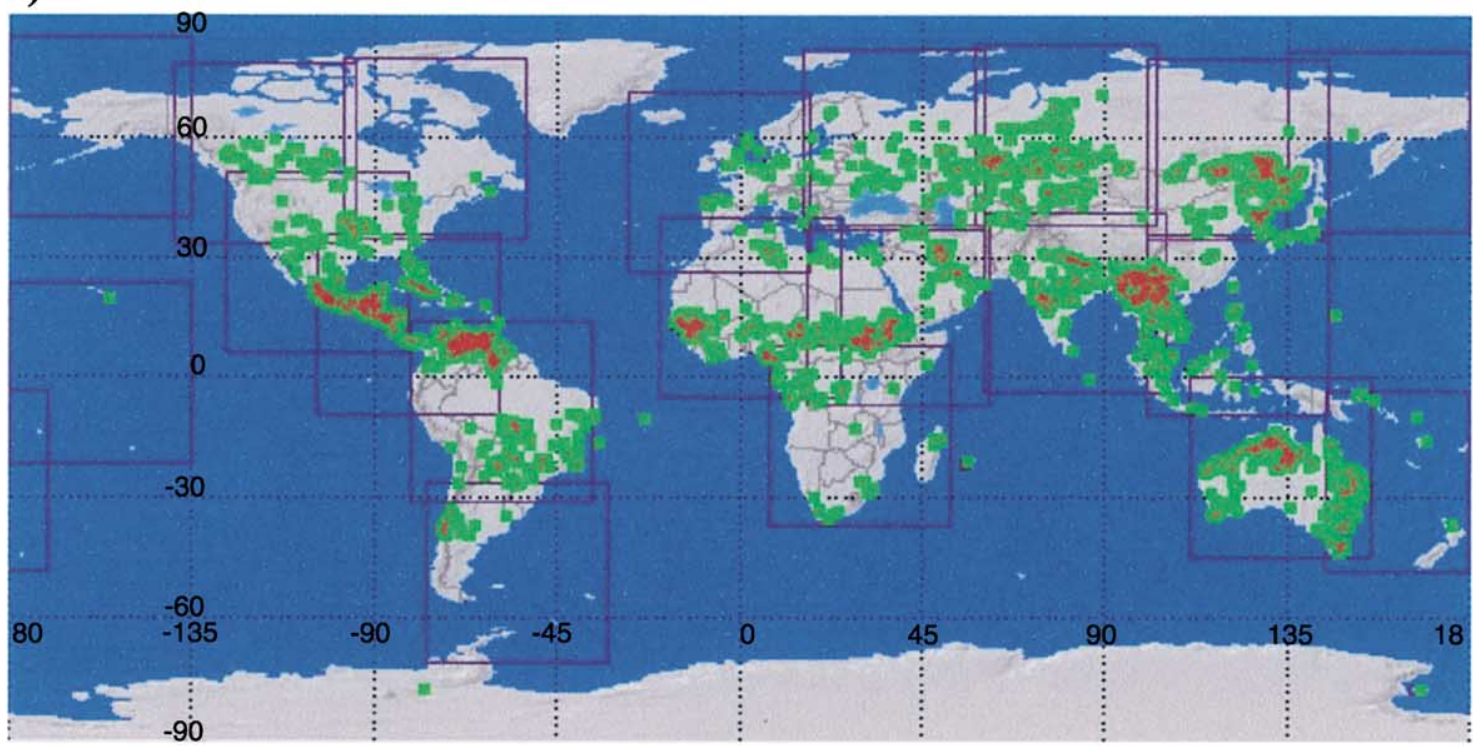

b)
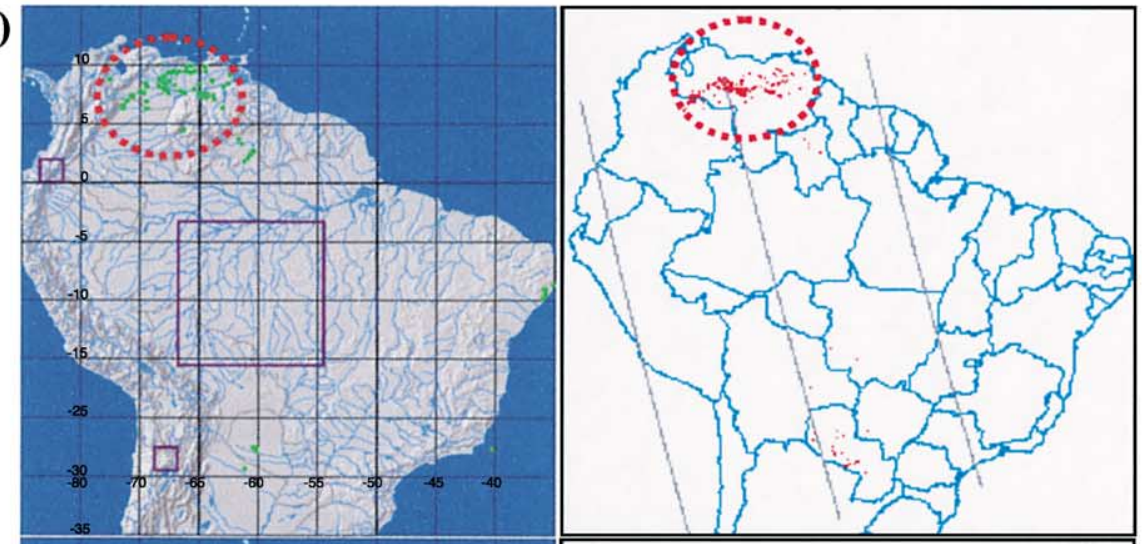

c)
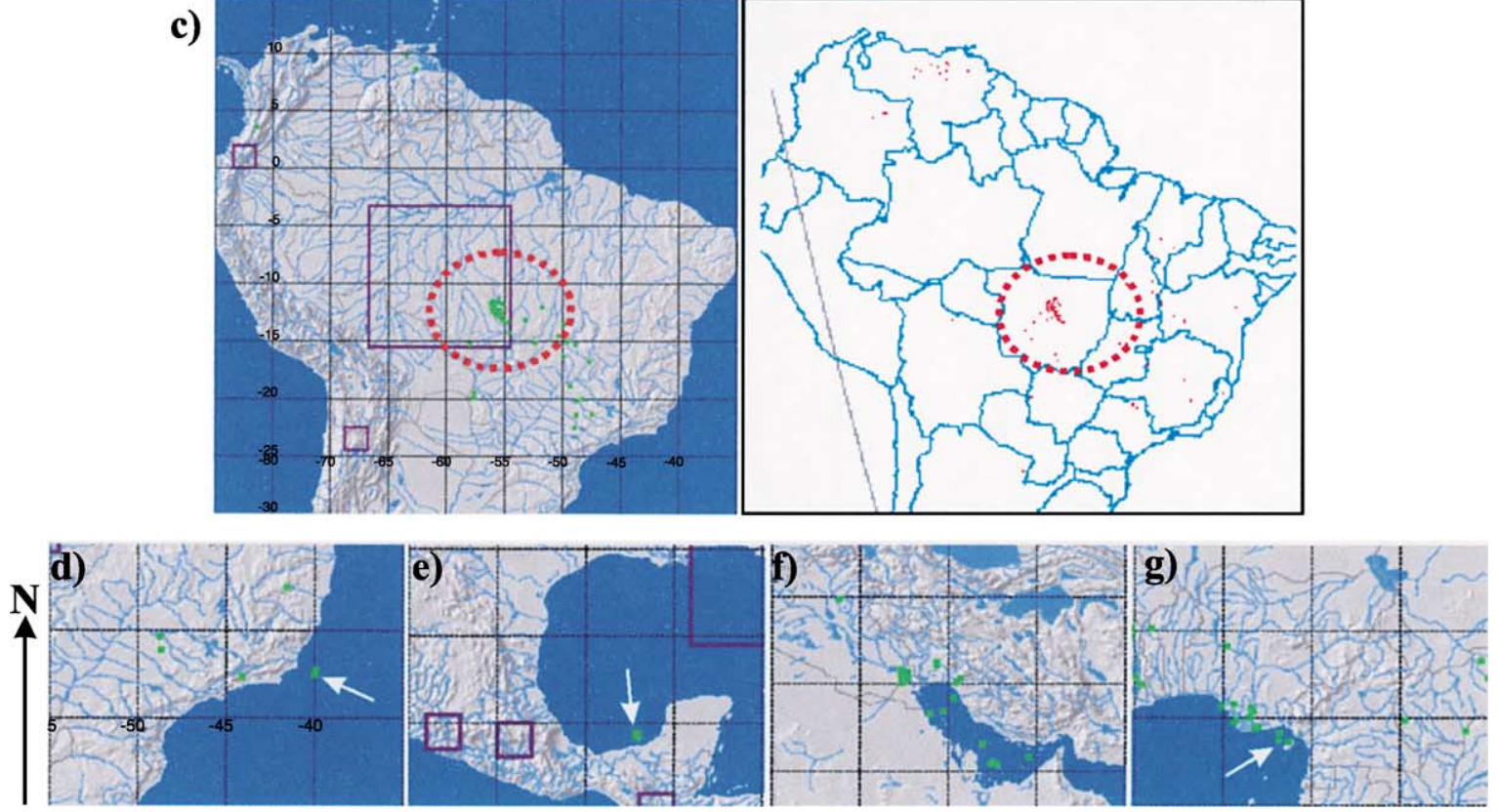
basic quantitative information for each hotspot detected, it is not intended to be an all-encompassing volcanic thermal analysis tool, and the original image data should be requested from the GSFC DAAC if the user intends to perform detailed thermal analysis. That the algorithm does not return image data as an output is itself a source of confusion when interpreting hotspot occurrence. Clearly, clouds prevent detection of hotspots, but without actual image data, it is impossible to deduce their impact.

Implementation of the MODVOLC algorithm was initially hampered by data processing bottlenecks at the GSFC DAAC (Flynn et al., in press), and as a result, several data gaps exist in our hotspot archive. However, this situation has improved markedly and at the time of writing (February 2002), the time lag between acquisition of the raw MODIS data and posting of the hotspot results on the MODVOLC website has fallen to between 24 and $48 \mathrm{~h}$. Thus, although we are not yet detecting volcanic eruptions in real time, we are certainly approaching a situation of near-real-time operation for the MODVOLC algorithm.

\section{Conclusions}

We have outlined how MODIS data can be used as the basis for an automated system to detect and monitor volcanic eruptions for the entire globe. Case studies from several volcanoes have shown the algorithm to be robust enough to detect a range of contrasting eruption styles and intensities, while yielding very few, if any, false alerts. By designing the algorithm to eliminate erroneous detection events, we realise that we forgo the detection of lowintensity hotspots, but we find this preferential to the situation in which the results of the algorithm cannot be trusted. The algorithm simultaneously provides a tool to monitor the distribution of wildfires and industrial hotspots.

Although this paper presents results pertaining to the analysis of nighttime MODIS data, we are currently testing a version of the MODVOLC algorithm that will run on the daytime MODIS data stream. When operational, this will allow two hotspot observations per day for most areas of the Earth. The launch of the second MODIS sensor on-board Aqua will further enhance the utility of the MODVOLC system, by allowing up to four hotspot observations to be made (morning, afternoon, evening, and night) in a 24-h period. This is important in terms of fire detection, as the morning and late-night overpass of Terra MODIS will miss the short-duration afternoon fires common in South America and Africa (Kaufman et al., 1998). It also has important implications for monitoring dynamic volcanic phenomenon, such as advancing lava flows, by providing a more dense temporal sample.

The examples described in this paper show that MODIS can be used to automatically detect and monitor spatially and temporally dynamic thermal phenomenon. When fully operational, we anticipate that MODVOLC and its associated website will provide an integrated resource for detecting, archiving, and disseminating information regarding the global occurrence of volcanic eruptions.

\section{Acknowledgements}

The authors were supported by NASA Pathfinder grant NAG5-9413. MODIS data were made available via the GSFC DAAC. We would like to thank Rich Hucek (NASA, GSFC) for, thus far, 7 years of valuable assistance without which MODVOLC would not have been implemented. We would also like to thank members of the MODLAND Fire Team (Chris Justice, Yoram Kaufman, Elaine Prins, Louis Giglio, Jackie Kendall) for insightful discussions regarding global hotspot detection. The paper benefited from informal discussions with D. Rothery (Open University) and from formal reviews provided by M. Wooster (King's College, London) and an anonymous referee. This is HIGP contribution number 1216 and SOEST contribution number 5976.

\section{References}

Barnes, W. L., Pagano, T. S., \& Salomonson, V. V. (1998). Prelaunch characteristics of the Moderate Resolution Imaging Spectroradiometer (MODIS) on EOS-AM1. IEEE Transactions in Geoscience and Remote Sensing, 36, 1088-1100.

Chester, D. K., Duncan, A. M., Guest, J. E., \& Kilburn, C. R. J. (1985) Mount Etna: the anatomy of a volcano (p. 404). Stanford: Stanford University Press.

Dehn, J., Dean, K., \& Engle, K. (2000). Thermal monitoring of North Pacific volcanoes from space. Geology, 28, 755-758.

Dozier, J. (1981). A method for satellite identification of surface temperature fields of subpixel resolution. Remote Sensing of Environment, 11, $221-229$.

Flasse, S. P., \& Ceccato, P. S. (1996). A contextual algorithm for AVHRR fire detection. International Journal of Remote Sensing, 17, 419-424.

Flynn, L. P., Harris, A. J. L., \& Wright, R. (2001). Improved identification of volcanic features using Landsat $7 \mathrm{ETM}+$. Remote Sensing of Environment, 79, $1-14$.

Flynn, L. P., Mouginis-Mark, P. J., Gradie, J. C., \& Lucey, P. G. (1993). Radiative temperature measurements at Kupaianaha lava lake, Kilauea Volcano, Hawai'i. Journal of Geophysical Reasearch, 98, 6461-6476.

Flynn, L. P., Mouginis-Mark, P. J., \& Horton, K. A. (1994). Distribution of thermal areas on an active lava flow field: landsat observations of Kilauea, Hawai'i, July 1991. Bulletin of Volcanology, 56, 284-296.

Flynn, L. P., Wright, R., Garbeil, H., Harris, A. J. L., \& Pilger, E. (2002). A global thermal alert using MODIS: initial results from 2000-2001. Advances in Environmental Monitoring and Modeling, 1, 5-36.

Francis, P. W., \& McAllister, R. (1986). Volcanology from space; using Landsat thematic mapper data in the Central Andes. Eos, Transactions of the American Geophysical Union, 67, 170-171.

GVN (2001a). Soufriere Hills. Bulletin of the Global Volcanism Network, 26(2), 7-9.

GVN (2001b). Etna. Bulletin of the Global Volcanism Network, 26(5), 6-7.

GVN (2001c). Nyamuragira. Bulletin of the Global Volcanism Network, 26(3), 7-8.

GVN (2001d). Nyamuragira. Bulletin of the Global Volcanism Network $26(1), 7$. 
GVN (2001e). Shiveluch. Bulletin of the Global Volcanism Network, 26(4), $2-4$.

GVN (2001f). Piton de la Fournaise. Bulletin of the Global Volcanism Network, 26(5), 4-6.

Harris, A. J. L., Blake, S., Rothery, D. A., \& Stevens, N. F. (1997). A chronology of the 1991 to 1993 Etna eruption using advanced very high resolution radiometer data: implications for real-time thermal volcano monitoring. Journal of Geophysical Research, 102, 7985-8003.

Harris, A. J. L., Flynn, L. P., Dean, K., Pilger, E., Wooster, M., Okubo, C., Mouginis-Mark, P., Garbeil, H., Thornber, C., De La Cruz-Reyna, S., Rothery, D., \& Wright, R. (2000). Real-time monitoring of volcanic hot spots with satellites. In P. J. Mouginis-Mark, J. A. Crisp, \& J. H. Fink (Eds.), Remote sensing of active volcanism. American Geophysical Union Monograph: Vol. 116. (pp. 139-159). (Washington, DC).

Harris, A. J. L., Flynn, L. P., Rothery, D. A., Oppenheimer, C., \& Sherman, S. B. (1999). Mass flux measurements at active lava lakes: implications for magma recycling. Journal of Geophysical Research, 104, 71177136.

Harris, A. J. L., Keszthelyi, L., Flynn, L. P., Mouginis-Mark, P. J., Thornber, C., Kauahikaua, J., Sherrod, D., Trusdell, F., Sawyer, M. W., \& Flament, P. (1997). Chronology of the episode 54 eruption at Kilauea Volcano, Hawai'i, from GOES-9 satellite data. Geophysical Research Letters, 24, 3281-3284.

Harris, A. J. L., Murray, J. B., Aries, S. E., Davies, M. A., Flynn, L. P., Wooster, M. J., Wright, R., \& Rothery, D. A. (2000). Effusion rate trends at Etna and Krafla and their implication for eruptive mechanisms. Journal of Volcanology and Geothermal Research, 102, 237-270 (Washington, DC) .

Harris, A. J. L., \& Neri, M. (in press). Volumetric observations of the 1999 Bocca Nuova eruption: pressurized drainage of a shallow chamber or pulsed supply? Journal of Volcanology and Geothermal Research.

Harris, A. J. L., Pilger, E., \& Flynn, L. P. (2002). Web-based hot spot monitoring using GOES: what it is and how it works. Advances in Environmental Monitoring and Modeling, 1, 37-69.

Harris, A. J. L., Pilger, E., Flynn, L. P., Garbeil, H., Mouginis-Mark, P. J., Kauahikaua, J., \& Thornber, C. (2001). Automated, high temporal resolution, thermal analysis of Kilauea volcano, Hawai'i, using GOES satellite data. International Journal of Remote Sensing, 22, 945-967.

Harris, A. J. L., \& Stevenson, D. S. (1997). Thermal observations of open degassing conduits and fumaroles at Stromboli and Vulcano using remotely sensed data. Journal of Volcanology and Geothermal Research, 76, 175-198.

Harris, A. J. L., Swabey, S. E. J., \& Higgins, J. (1995). Automated thresholding of active lavas using AVHRR data. International Journal of Remote Sensing, 16, 3681-3686.

Harris, A. J. L., \& Thornber, C. R. (1999). Complex effusive events at Kilauea as documented by the GOES satellite and remote video cameras. Bulletin of Volcanology, 61, 382-395.

Harris, A. J. L., Wright, R., \& Flynn, L. P. (1999). Remote monitoring of Mount Erebus Volcano, Antarctica, using Polar orbiters: progress and prospects. International Journal of Remote Sensing, 20, 3051-3071.

Kaufman, Y. J., Justice, C. O., Flynn, L. P., Kendall, J. D., Prins, E. M., Giglio, L., Ward, D. E., Menzel, W. P., \& Setzer, A. W. (1998). Potential global fire monitoring from EOS-MODIS. Journal of Geophysical Research, 103, 32215-32238.

Klett, T. R., Ahlbrandt, T. S., Schmoker, J. W., \& Dolton, G. L. (1997). Ranking of the world's oil and gas provinces by known petroleum volumes. USGS Open-File Report 97-463.
Mouginis-Mark, P. J., Snell, H., \& Ellisor, R. (2000). GOES satellite and field observations of the 1998 eruption of Volcan Cerro Azul, Galápagos Islands. Bulletin of Volcanology, 62, 188-198.

Oppenheimer, C., Francis, P. W., Rothery, D. A., Carlton, R. W. T., \& Glaze, L. S. (1993). Infrared image analysis of volcanic thermal features: Lascar Volcano, Chile, 1984-1992. Journal of Geophysical Research, 98, 4269-4286.

Prins, E. M., \& Menzel, W. P. (1992). Geostationary satellite detection of biomass burning in South America. International Journal of Remote Sensing, 13, 2783-2799.

Prins, E. M., \& Menzel, W. P. (1994). Trends in South American biomass burning detected with the GOES visible infrared spin scan radiometer atmospheric sounder from 1983 to 1991. Journal of Geophysical Research, 99, 16719-16735.

Rothery, D. A., Coltelli, M., Pirie, D., Wooster, M. J., \& Wright, R. (2001). Documenting surface magmatic activity at Mount Etna using ATSR remote sensing. Bulletin of Volcanology, 63, 387-397.

Rothery, D. A., Thorne, M. T., \& Flynn, L. P. (in press). MODIS hot spot alerts in Britain and the North Sea during the first half of 2001. International Journal of Remote Sensing.

Schneider, D. J., Dean, K. G., Dehn, J., Miller, T. P., \& Kirianov, V. U. (2000). Monitoring and analyses of volcanic activity using remote sensing data at the Alaska Volcano Observatory: case study for Kamchatka, Russia, December 1997. In P. J. Mouginis-Mark, J. A. Crisp, \& J. H. Fink (Eds.), Remote sensing of active volcanism. American Geophysical Union Monograph: Vol. 116. (pp. 65-85). (Washington, DC).

Simkin, T., \& Siebert, L. (1994). Volcanoes of the world (2nd ed.) (p. 368). Tucson, AZ: Geoscience Press.

Tazieff, H. (1994). Permanent lava lakes: observed facts and induced mechanisms. Journal of Volcanology and Geothermal Research, 63, 3-11.

Wadge, G. (1981). The variation of magma discharge during basaltic eruptions. Journal of Volcanology and Geothermal Research, 11, 139-168.

Wooster, M. J. (2001). Long-term infrared surveillance of Lascar Volcano: contrasting activity cycles and cooling pyroclastics. Geophysical Research Letters, 28, 847-850.

Wooster, M. J., \& Kaneko, T. (1998). Satellite thermal analyses of lava dome effusion rates at Unzen Volcano, Japan. Journal of Geophysical Research, 103, 20935-20947.

Wooster, M. J., Kaneko, T., Nakada, S., \& Shimizu, H. (2000). Discrimination of lava dome activity styles using satellite-derived thermal structures. Journal of Volcanology and Geothermal Research, 102, 97-118.

Wright, R., de la Cruz-Reyna, S., Flynn, L. P., Harris, A. J. L., \& GomezPalacios, J. J. (in press). Infrared satellite monitoring at Popocatepétl: explosions, exhalations, and cycles of dome growth. Journal of Geophysical Research.

Wright, R., Flynn, L. P., \& Harris, A. J. L. (2001). Evolution of lava flowfields at Mount Etna, 27-28 October 1999, observed by Landsat 7 $\mathrm{ETM}+$. Bulletin of Volcanology, 63, 1-7.

Wright, R., Rothery, D. A., Blake, S., \& Pieri, D. C. (2000). Improved remote sensing estimates of lava flow cooling: a case study of the 1991 -1993 Mount Etna eruption. Journal of Geophysical Research, 105, 23681-23694.

Young, S. R., Sparks, R. S. J., Aspinall, W. P., Lloyd, L. L., Miller, A. D., Robertson, R. E. A., \& Shepherd, J. B. (1998). Overview of the eruption of Soufriere Hills Volcano, Montserrat, 18 July 1995 to December 1997. Geophysical Research Letters, 25, 3389-3392. 